\title{
Measurement of Slope Deformation Using Quadrilaterals
}

\section{U.S. GEOLOGICAL SURVEY BULLETIN 1842-B}

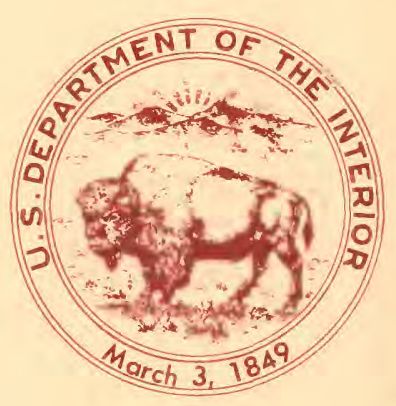




\section{AVAILABILITY OF BOOKS AND MAPS OF THE U.S. GEOLOGICAL SURVEY}

Instructions on ordering publications of the U.S. Geological Survey, along with prices of the last offerings, are given in the current-year issues of the monthly catalog "New Publications of the U.S. Geological Survey." Prices of available U.S. Geological Survey publications released prior to the current year are listed in the most recent annual "Price and Availability List." Publications that are listed in various U.S. Geological Survey catalogs (see back inside cover) but not listed in the most recent annual "Price and Availability List" are no longer available.

Prices of reports released to the open files are given in the listing "U.S. Geological Survey Open-File Reports," updated monthly, which is for sale in microfiche from the U.S. Geological Survey, Books and Open-File Reports Section, Federal Center, Box 25425 , Denver, CO 80225 . Reports released through the NTIS may be obtained by writing to the National Technical Information Service, U.S. Department of Commerce, Springfield, VA 22161; please include NTIS report number with inquiry.

Order U.S. Geological Survey publications by mail or over the counter from the offices given below.

\section{BY MAIL}

\section{Books}

Professional Papers, Bulletins, Water-Supply Papers, Techniques of Water-Resources Investigations, Circulars, publications of general interest (such as leaflets, pamphlets, booklets), single copies of Earthquakes \& Volcanoes, Preliminary Determination of Epicenters, and some miscellaneous reports, including some of the foregoing series that have gone out of print at the Superintendent of Documents, are obtainable by mail from

\section{U.S. Geological Survey, Books and Open-File Reports Federal Center, Box 25425 Denver, CO 80225}

Subscriptions to periodicals (Earthquakes \& Volcanoes and Preliminary Determination of Epicenters) can be obtained ONLY from the

\section{Superintendent of Documents \\ Government Printing Office \\ Washington, D.C. 20402}

(Check or money order must be payable to Superintendent of Documents.)

\section{Maps}

For maps, address mail orders to

\section{U.S. Geological Survey, Map Distribution \\ Federal Center, Box 25286 \\ Denver, CO 80225}

Residents of Alaska may order maps from

Alaska Distribution Section, U.S. Geological Survey, New Federal Building - Box 12 101 Twelfth Ave., Fairbanks, AK 99701

\section{OVER THE COUNTER}

\section{Books}

Books of the U.S. Geological Survey are available over the counter at the following Geological Survey Public Inquiries Offices, all of which are authorized agents of the Superintendent of Documents:

- WASHINGTON, D.C.--Main Interior Bldg., 2600 corridor, 18 th and C Sts., NW.

- DENVER, Colorado--Federal Bldg., Rm. 169, 1961 Stout St.

- LOS ANGELES, California--Federal Eldg., Rm. 7638, 300 N. Los Angeles St.

- MENLO PARK, California--Bldg. 3 (Stop 533), Rm. 3128. 345 Middlefield Rd.

- RESTON, Virginia--503 National Center, Rm. 1C402, 12201 Sunrise Valley Dr.

- SALT LAKE CITY, Utah--Federal Bldg., Rm. 8105, 125 South State St.

- SAN FRANCISCO, Callfornia--Customhouse, Rm. 504, 555 Battery St.

- SPOKANE, Washington--U.S. Courthouse, Rm. 678, West 920 Riverside Ave.

- ANCHORAGE, Alaska-Rm. 101, 4230 University Dr.

- ANCHORAGE, Alaska--Federal Bldg, Rm. E-146, 701 C St.

\section{Maps}

Maps may be purchased over the counter at the U.S. Geological Survey offices where books are sold (all addresses in above list) and at the following Geological Survey offices:

- ROLLA, Missouri--1400 Independence Rd.

- DENVER, Colorado--Map Distribution, Bldg. 810, Federal Center

- FAIRBANKS, Alaska--New Federal Bldg., 101 Twelfth Ave. 
Chapter B

\section{Measurement of Slope Deformation Using Quadrilaterals}

By Rex L. Baum, Arvid M. Johnson, and Robert W. Fleming

A description of a new method for measuring displacement at the boundaries of a landslide and strain and tilt at the surface of a landslide

U.S. Geological Survey Bulletin 1842 
DEPARTMENT OF THE INTERIOR

DONALD PAUL HODEL, Secretary

\section{U. S. GEOLOGICAL SURVEY}

Dallas L. Peck, Director

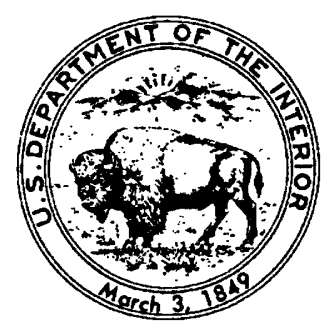

For sale by the

Books and Open-File Reports Section

U.S. Geological Survey

Federal Center

Box 25425

Denver, CO 80225

\section{Library of Congress Cataloging in Publication Data}

Measurement of slope deformation using quadrilaterals.

(U.S. Geological Survey bulletin ; 1842) (Landslide processes in Utah-observation and theory; ch. B)

Bibliography: $p$.

1. Landslides-Utah. 2. Slopes (Soil

mechanics)-Utah. 3. Quadrilaterals. I. Johnson, Arvid M. II. Fleming,

Robert W. III. Title. IV. Series. V. Series: Landslide processes in

Utah-observation and theory ; ch. B.

QE75.B9 no.1842-B

557.3 s [551.3'53]

$88-600370$

[QE599.U] 


\section{CONTENTS}

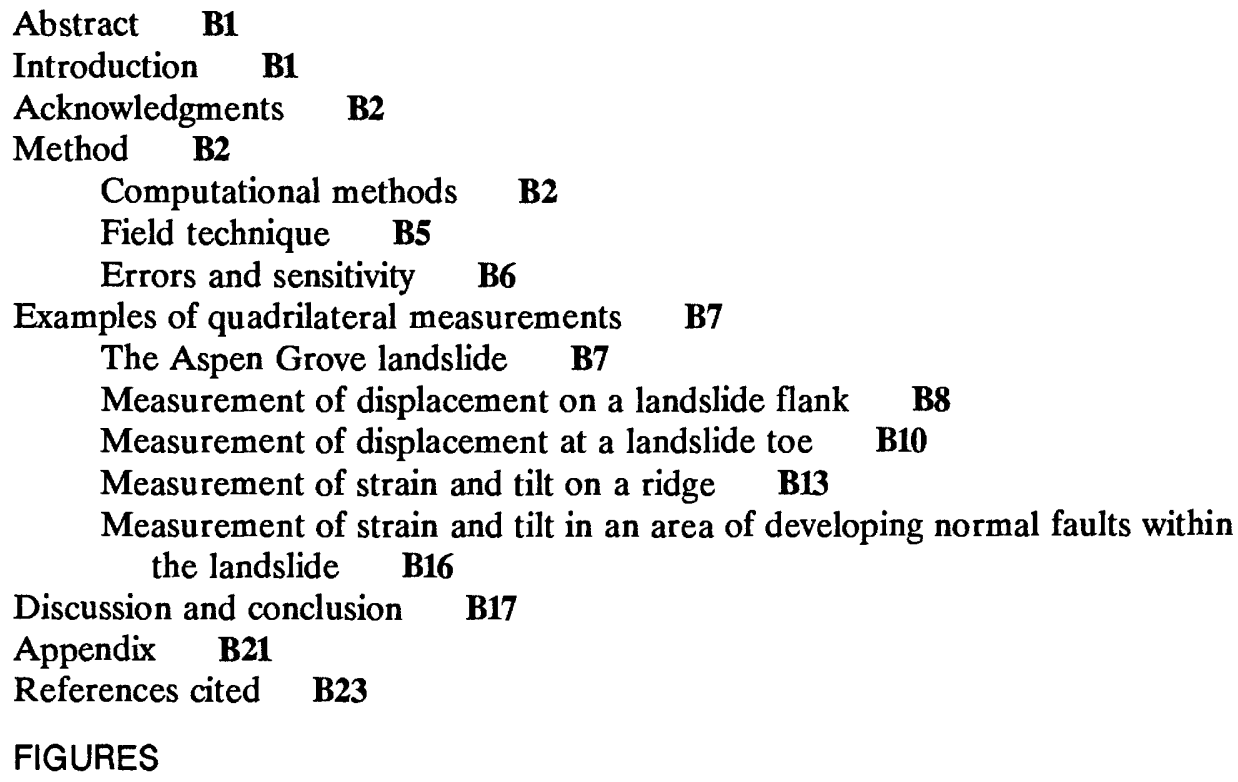

B1. Sketch showing typical quadrilateral. B2

B2. Sketch of reference system for computing displacements across a discontinuity or landslide boundary B4

B3. Diagram showing geometrical relationships between a deformed triangle and its stretch ellipse B5

B4. Diagram showing dip direction of triangle $A B C \quad \mathbf{B 5}$

B5. Map showing location of the Aspen Grove landslide, central Utah B8

B6. Map showing the Aspen Grove landslide, August $1984 \quad$ B9

B7. Sketch of the site of Q-2 on June 15, 1983 B10

B8. Map showing part of the Aspen Grove landslide in vicinity of quadrilateral Q-2 during August $1984 \quad$ B11

B9. Map and cross section showing internal toe of the Aspen Grove landslide B12

B10. Graph showing displacements of stake $A$ at Q-27 from May 18 to August 4, $1984 \quad$ B13

B11. Enlarged view of area "d", shown in figure B9 B14

B12. Map showing ridge on the right flank of the Aspen Grove landslide, August $1984 \quad$ B15

B13. Polar plot showing attitude (dip and dip directions) of the four triangles in quadrilateral Q-34 B16

B14-B16. Map showing part of the Aspen Grove landslide in the vicinity of Q-5 during:

B14. August $1984 \quad$ B18

B15. August $1985 \quad$ B19

B16. September 1986

B20 


\section{TABLES}

B1. Principal strains at Q-34 B16

B2. Strains in Quadrilateral Q-5 B17

CONVERSION FACTORS

\begin{tabular}{lll}
\hline \multicolumn{1}{c}{ Multiply } & \multicolumn{1}{c}{ By } & To obtain \\
\hline mm (millimeters) & 0.03937 & in. (inches) \\
cm (centimeters) & 0.3937 & in. (inches) \\
m (meters) & 3.2808 & ft (feet) \\
km (kilometers) & 0.6214 & mi (miles) \\
\hline
\end{tabular}




\section{LIST OF SYMBOLS}

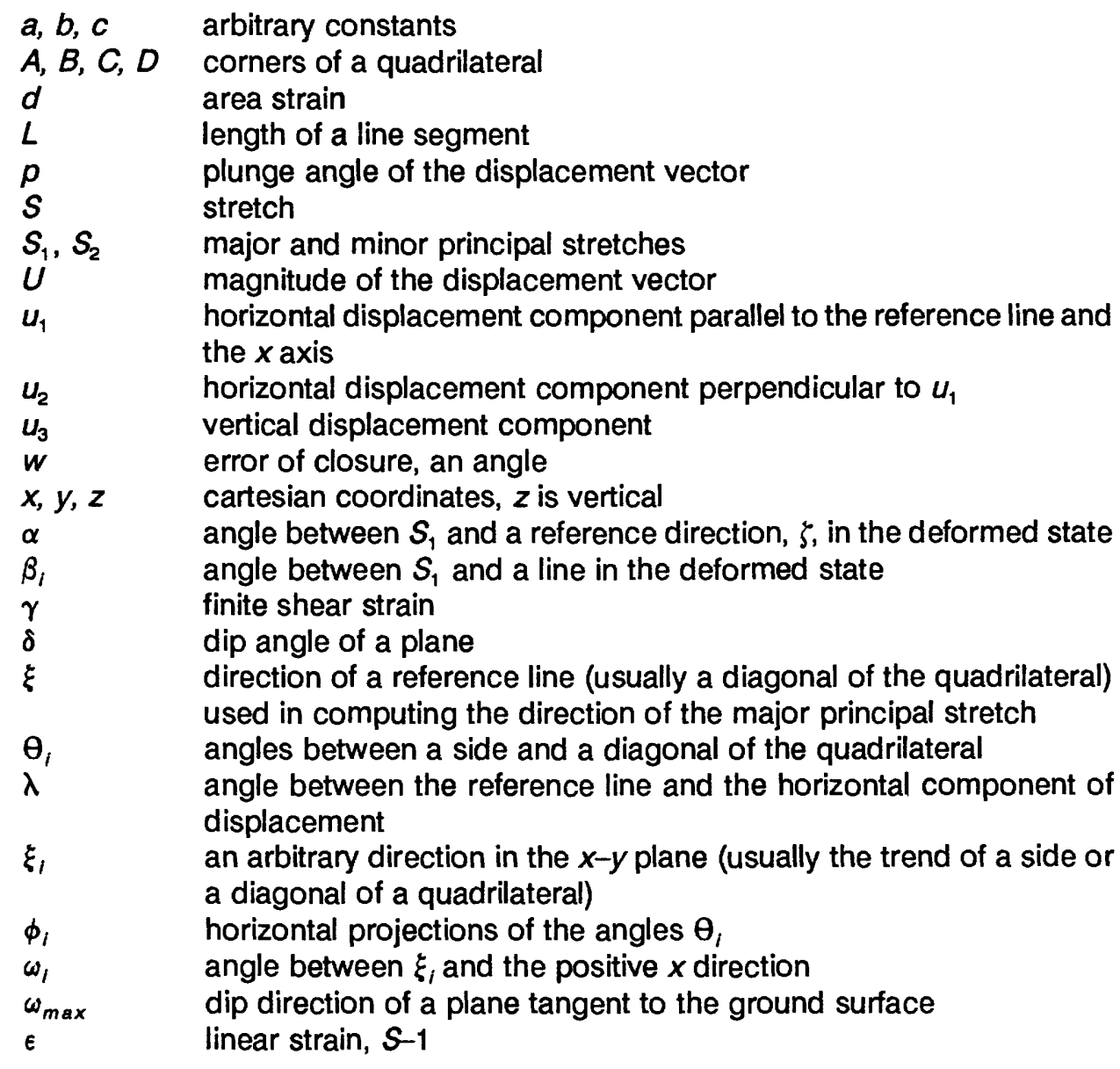

Primes denote positions or values in the deformed state 



\title{
Measurement of Slope Deformation Using Quadrilaterals
}

\author{
By Rex L. Baum ${ }^{1}$, Arvid M. Johnson ${ }^{2}$, and Robert W. Fleming ${ }^{1}$
}

\begin{abstract}
Quadrilaterals, four-sided figures defined by survey stakes at their four corners, were used to measure deformation of the ground surface at a landslide in central Utah. The lengths of the sides and diagonals and the vertical distances between the corners of each quadrilateral were measured at intervals of days or weeks to observe changes.

Equations were derived for computing threedimensional displacements of corners of a quadrilateral that straddles a landslide boundary. Equations were also derived for computing the magnitude and orientation of principal stretches and the initial and final dips and dip directions of each of four triangles defined by the perimeter and diagonals of a quadrilateral on the surface of a landslide.

Length measurements were made with a steel tape and elevation differences between the tops of stakes were measured by taking backsights with a precision level. For the measurement technique used, we observed the following: Errors of 5-6 mm occurred in 10-20 percent of our length measurements. Because the landslide moved at rates of several millimeters to several centimeters per day, displacements could be computed from data sets measured at intervals of two or three days. However, strains could be computed only from data sets measured at intervals of many weeks. Square quadrilaterals, from 1.5 to $4.0 \mathrm{~m}$ wide, worked best for observing deformation.

Twenty-eight quadrilaterals were used to measure deformation on a long, narrow landslide; in general, the quadrilaterals functioned very well. For example, at a small quadrilateral on the flank of the landslide, displacements of a few meters occurred before the stakes had to be relocated in order to continue using the quadrilateral. Several centimeters of displacement occurred at a quadrilateral on an internal toe of the landslide before thrust faults appeared at the surface of the toe. Tilt of $1^{\circ}-2^{\circ}$ was measured at a quadrilateral on the
\end{abstract}

\footnotetext{
80225 .

${ }^{2}$ Purdue University, West Lafayette, Indiana.
}

${ }^{1}$ U.S. Geological Survey, Box 25046, M.S. 966, Denver, CO side of a deforming flank ridge. Another quadrilateral documented the deformation that preceded the appearance of a normal fault within the boundaries of the landslide.

\section{INTRODUCTION}

Displacements and strains have been used in many studies of slope behavior. Such data are useful for studying landslide kinematics and dynamics (Keefer and Johnson, 1983; Iverson, 1984; Lantz, 1984), monitoring stability of slopes and safety of structures during and after construction (Hanna, 1985), planning and evaluating landslide stabilization schemes (TerStepanian, 1984), measuring near-surface stresses in slopes (Zaruba and Mencl, 1982), and estimating the geometry of slip surfaces (Carter and Bentley, 1985; Cruden, 1986). These applications have in common an attempt to use surface measurements to infer conditions at depth.

In order to understand and possibly predict some aspects of landslide behavior by means of surface measurements, monitoring was begun at some of the landslides that occurred in Utah during 1983. Quadrilaterals were installed at several places on a landslide in central Utah, at the suggestion of David Varnes (U.S. Geological Survey). Such a technique was also proposed by Brunsden (1984, p. 393, 396), who indicated that no published accounts exist of the use of quadrilaterals in studying landslides.

In surveying, a quadrilateral is a four-sided, plane figure defined by the survey stations (stakes or monuments) at its four corners (Ingram, 1972; Brinker and Wolf, 1977; Laurila, 1983). Brinker and Wolf (1977, p. 372) noted that the quadrilateral is the simplest geometric figure that permits rigorous closure checks 
and adjustment of measurement errors. Errors of closure can be determined because a redundant measurement is made whenever the lengths of all four sides and both diagonals of the quadrilateral are measured. Various methods are used to distribute the error (Laurila, 1983).

In addition to the fact that the measurements of quadrilaterals can be checked and adjusted rigorously, quadrilaterals have several features that make them useful for measuring strains and displacements. Quadrilaterals permit measurement of strain in several directions at one location because the sides and diagonals trend in as many as six different compass directions. Because quadrilaterals are defined by survey stations at their four corners, soil within a quadrilateral can undergo large deformations without the quadrilateral affecting soil movement. This is a distinct advantage over some types of soil strain gages (Hanna, 1985, p. 296-300). Quadrilaterals can be measured with a variety of instruments, such as a steel tape, a tape extensiometer, or a sophisticated electronic device. Thus, they can be used to make measurements at levels of precision needed for a wide variety of landslide studies.

Experience with the use of quadrilaterals during the last few years has convinced us that the method has significant potential for studying landslide kinematics. We have learned, by trial and error, how quadrilaterals can be expected to function in field situations. This paper explains the theory behind the use of quadrilaterals and describes how quadrilaterals were used in the field. The use of the data for describing the kinematics of the landslide is discussed in another chapter of this bulletin.

\section{ACKNOWLEDGMENTS}

David J. Varnes (USGS, Denver) suggested the use of quadrilaterals and helped with fieldwork. Roger Johnson (Ephraim, Utah), Chad Parry (Ephraim, Utah), Douglas Robins (Gunnison, Utah), Roger Nichols (USGS, Denver), Lee-Ann Chandler (USGS, Denver), and Gary Jorgenson (USFS, Ephraim, Utah) helped with fieldwork. Ben Black (Manti District Ranger, USFS, Ephraim, Utah) shared observations and helped solve various logistical problems. We express our sincere appreciation to all these people.

\section{METHOD}

Here we discuss the theory behind the use of quadrilaterals and some practical details that apply to all quadrilaterals: the fundamentals of computing displacements, strains, and tilts (derivations of the equations for finite strain are in Appendix); the optimum range of size, shape, and frequency of measurement of the quadrilaterals; and detecting and dealing with the measurement errors.

\section{Computational Methods}

In the field, a quadrilateral is marked by stakes or permanent markers at its four corners (fig. B1). Measurements of the lengths of the sides and diagonals are repeated to observe deformation of the quadrilateral through time.

If the quadrilateral straddles an outer edge of the landslide, then the data are used to compute landslide displacements relative to the stable ground along the boundary. If the quadrilateral is within the landslide, then the data are used to compute strains and tilts within the landslide mass.

Errors. - Detailed theories for checking closure and adjusting measurement errors in quadrilaterals are in the surveying literature (Ingram, 1972; Brinker and Wolf, 1977; Laurila, 1983; and others).

We compute the error of closure by projecting the quadrilateral onto a horizontal plane. Angles $\phi_{1}, \ldots, \phi_{8}$, the horizontal projections of angles $\theta_{1}, \ldots, \theta_{8}$, shown in figure 1 , are computed by means of the law of cosines. The angular error of closure is determined by using the following equation (Laurila, 1983, p. 43):

$$
w=\left(\sum_{i=1}^{8} \phi_{i}\right)-360^{\circ} \text {. }
$$

Displacement.-Displacement across a landslide boundary is computed from the original and final positions of a corner of the quadrilateral (fig. B2). The $x-y$

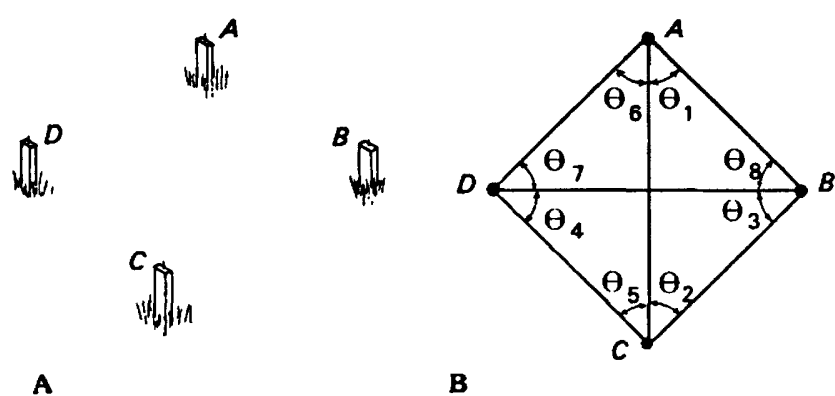

Figure B1. Sketch showing typical quadrilateral. (A) Isometric View, (B) Normal view. Stakes are labeled $A$ through $D$ in clockwise rotation, with stake $A$ having the highest elevation. Slope lengths of the four sides and two diagonals and the vertical distances (elevation differences) between $A$ and the other three corners are measured. Angles $\theta_{1}, \ldots, \theta_{8}$ are computed from the slope lengths of the sides and diagonals of the quadrilateral, by the law of cosines. 
plane is horizontal, with the positive $x$-axis being the horizontal projection of side $A D$ of the quadrilateral (figs. B1B, B2A). Angle $\phi$ (fig. B2B) for the initial position of corner $B$ of the quadrilateral is computed from the horizontal components of $A B, B D$, and $D A$ by means of the law of cosines. Similarly, angle $\phi^{\prime}$ for the final position of corner $B$, is computed from the horizontal components of $A B^{\prime \prime}, B^{\prime} D$, and $D A$. The $x$ and $y$ components of line $A B$ and the $x$ and $y$ components of line $A B^{\prime}$ are computed by means of standard trigonometric formulas. The $x$ and $y$ components of displacement, $u_{1}$ and $u_{2}$, (fig. B2) are determined by:

and,

$$
u_{1}=x^{\prime}-x,
$$

$$
u_{2}=y^{\prime}-y \text {. }
$$

The vertical component of displacement, $u_{3}$, is the elevation difference between $B$ and $B^{\prime}$. Total displacement (net slip), $U$, is determined by the Pythagorean theorem:

$$
U=\left(u_{1}^{2}+u_{2}{ }^{2}+u_{3}{ }^{2}\right)^{1 / 2} .
$$

The counterclockwise angle $\lambda$ between the positive $x$-axis and the horizontal component of displacement of corner $B$ is:

$$
\lambda=\tan ^{-1}\left(u_{2} / u_{1}\right) \text {. }
$$

Plunge, $p$, of the displacement is determined by:

$$
p=\tan ^{-1}\left(u_{3} /\left(u_{2}^{2}+u_{1}^{2}\right)^{1 / 2}\right) .
$$

In this way, one determines the magnitude, azimuth, and plunge of displacements at a point on the landslide. Similar calculations are performed to compute displacements of the second point, $C$.

Strains. - The differences in displacement of corners $B$ and $C$ of the quadrilateral, used to measure displacement at a landslide boundary (fig. B2A), define the strain between the corners. Also, by comparing the original length of line $B C$ to its final length, $B^{\prime} C^{\prime}$, stretch parallel to $B^{\prime} C^{\prime}$ can be determined.

More detailed information about the strain can be obtained at a quadrilateral on the surface of the landslide. If all four corners of the quadrilateral are coplanar and remain so during deformation, then one set of principal strains for the quadrilateral can be computed by the method of least squares (Appendix). However, the corners seldom are coplanar. Therefore, a set of principal strains is computed, in the plane of the triangle, for each of the four triangles making the quadrilateral (fig. B1), $\triangle A B C, \triangle B C D, \triangle C D A, \triangle D A B$. Each set of strains comprises the major and minor principal strains and the angle between the major principal strain and a reference direction for the quadrilateral.

Strains larger than 0.01 (1.0 percent) are treated as finite strains. A convenient measure of finite strain is the stretch $^{1}, S$ (Malvern, 1969; A.M. Johnson, unpub. data, 1981), which is the ratio of the final length, $L_{f}$, to the initial length, $L_{o}$ of a line segment:

$$
S=L_{f} / L_{o} .
$$

The linear strain, $\epsilon$ is

$$
\epsilon=S-1 \text {. }
$$

In two dimensions, the stretch can be described by an ellipse as in figure B3 (Ramsay, 1967; Ragan, 1973; A.M. Johnson, unpub. data, 1981).

$$
1=\left(x_{1} / S_{1}\right)^{2}+\left(x_{2} / S_{2}\right)^{2} \text {. }
$$

In equation 6, the major and minor principal stretches are $S_{1}$ and $S_{2}$, respectively. The clockwise angle between $S_{1}$ and a given side of the triangle is $\alpha$ (fig. B3). The nondimensional coordinate $x_{1}$ is parallel to $S_{1}$, and $x_{2}$ is parallel to $S_{2}$. The radius of the circle deformed into the ellipse is equal to one.

The stretches within each triangular strain gauge (that is, each group of three stakes in the quadrilateral) are fully determined because values of stretch, $S$, are known in three directions. In each triangle, $S_{1}, S_{2}$, and $\alpha$ constitute three unknowns that can be determined by solving three equations relating the unknowns to the three stretches (see Appendix for solution of the equations).

Once $S_{1}, S_{2}$, and $\alpha$ are known, they may be used to compute the area strain, the finite shear strain $\gamma$, and the stretch, $S$, in any direction (Jaeger, 1962; Ramsay, 1967; Ragan, 1973; A.M. Johnson, unpub. data, 1981). The area strain is $d$ :

$$
d=S_{1} S_{2}-1 \text {. }
$$

The maximum finite shear strain is $\gamma_{\max }$ :

$$
\gamma_{\max }=\left(S_{1}{ }^{2}-S_{2}{ }^{2}\right) /\left(2 S_{1} S_{2}\right)
$$

Tilt.-Tilt is the difference between the initial and final amount of dip of any triangle in the quadrilateral. Similarly, change in dip direction is defined as the angle between the initial and final dip direction of a triangle.

\footnotetext{
${ }^{1}$ The quadratic elongation or quadratic extension, widely used in structural geology, is equal to the stretch squared $\left(S^{2}\right)$. For elongation, $S$ is greater than 1 , and for shortening, $S$ is less than 1 . Of course, the principal values of the right Cauchy-Green tensor are $S_{1}{ }^{2}$ and $S_{2}^{2}$.
} 


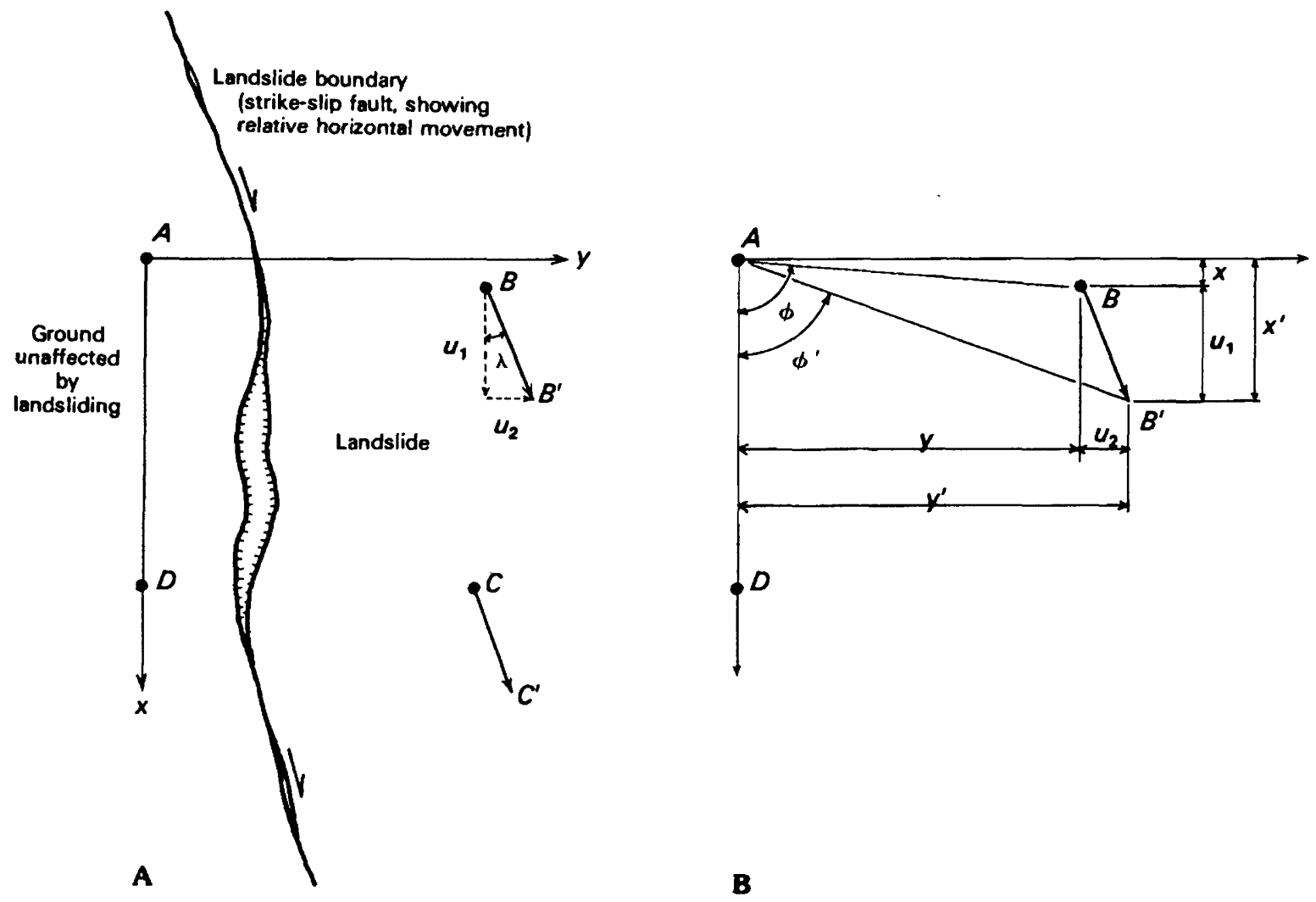

Figure B2. Sketch of reference system for computing displacements across a discontinuity or landslide boundary. The $x-y$ plane is horizontal; the origin is at point $A$ and the positive $x$ direction coincides with the direction of line $A D$. (A) Displacement component $u_{1}$ is parallel to $x, u_{3}$ (not shown) is vertical, and $u_{2}$ is parallel to $y$. The angle between the horizontal projection of the total displacement and the $x$ axis is $\lambda$. (B) Initial position of point $B$ is given by coordinates $x, y$, its final position, $B^{\prime}$, by coordinates $x^{\prime}, y^{\prime}$. The projection of angle $D A B$ onto the $x-y$ plane is $\phi$; that of angle $D A B^{\prime}$ is $\phi^{\prime}$.

Both are useful in interpreting strain data. Tilt shows whether the ground is steepening or flattening, and it is related to differences in the rate of thickening from one side of the quadrilateral to the other. Changes in the dip direction relate the tilt to changes in the shape of surface features.

The amount of dip and the dip direction of a triangle are computed as follows: The sides of a triangle correspond to coordinate directions $\xi_{i}$ in the $x-y$ plane, and the azimuths of those directions are $\omega_{i}$ (fig. B4). The slope $\left(\partial z / \partial \xi_{i}\right)$ and the azimuth $\left(\omega_{i}\right)$ of each side of the triangle are computed from field data. The slope of a line in any arbitrary direction $\xi_{i}$ within a plane is computed by differentiating the equation of a plane,

$$
z=a x+b y
$$

with respect to $\xi_{i}$ and making the substitutions

$$
\begin{gathered}
\cos \left(\omega_{i}\right)=\left(\partial \mathrm{x} / \partial \xi_{i}\right), \text { and } \sin \left(\omega_{i}\right)=\left(\partial \mathrm{y} / \partial \xi_{i}\right): \\
\left(\partial \mathrm{z} / \partial \xi_{1}\right)=a \cos \left(\omega_{1}\right)+b \sin \left(\omega_{1}\right) ;
\end{gathered}
$$

$$
\left(\partial z / \partial \xi_{2}\right)=a \cos \left(\omega_{2}\right)+b \sin \left(\omega_{2}\right) .
$$

In these equations, $a$ and $b$ are constants describing the slope of the plane in the $x$ and $y$ directions, respectively. Using the slopes of two sides of the triangle, one solves the set of equations, $7 \mathrm{a}$ and $7 \mathrm{~b}$, simultaneously for $a$ and $b$. The azimuth of the dip direction, which is the direction of maximum slope, is found by differentiating equation 7 with respect to $\omega$, letting the derivative of equation 7 equal zero, and solving for $\omega_{\max }$ :

$$
\omega_{\max }=\tan ^{-1}(b / a) .
$$

The tangent of the dip angle, $\delta$, is derived by substituting the azimuth of the dip direction, $\omega_{\max }$, back into equation 7 and solving for $\left(\partial z / \partial \xi_{\max }\right)$, the tangent.

and

$$
\tan (\delta)=a \cos \left(\omega_{\max }\right)+b \sin \left(\omega_{\max }\right),
$$

$$
\delta=\tan ^{-1}\left[a \cos \left(\omega_{\max }\right)+b \sin \left(\omega_{\max }\right)\right] .
$$




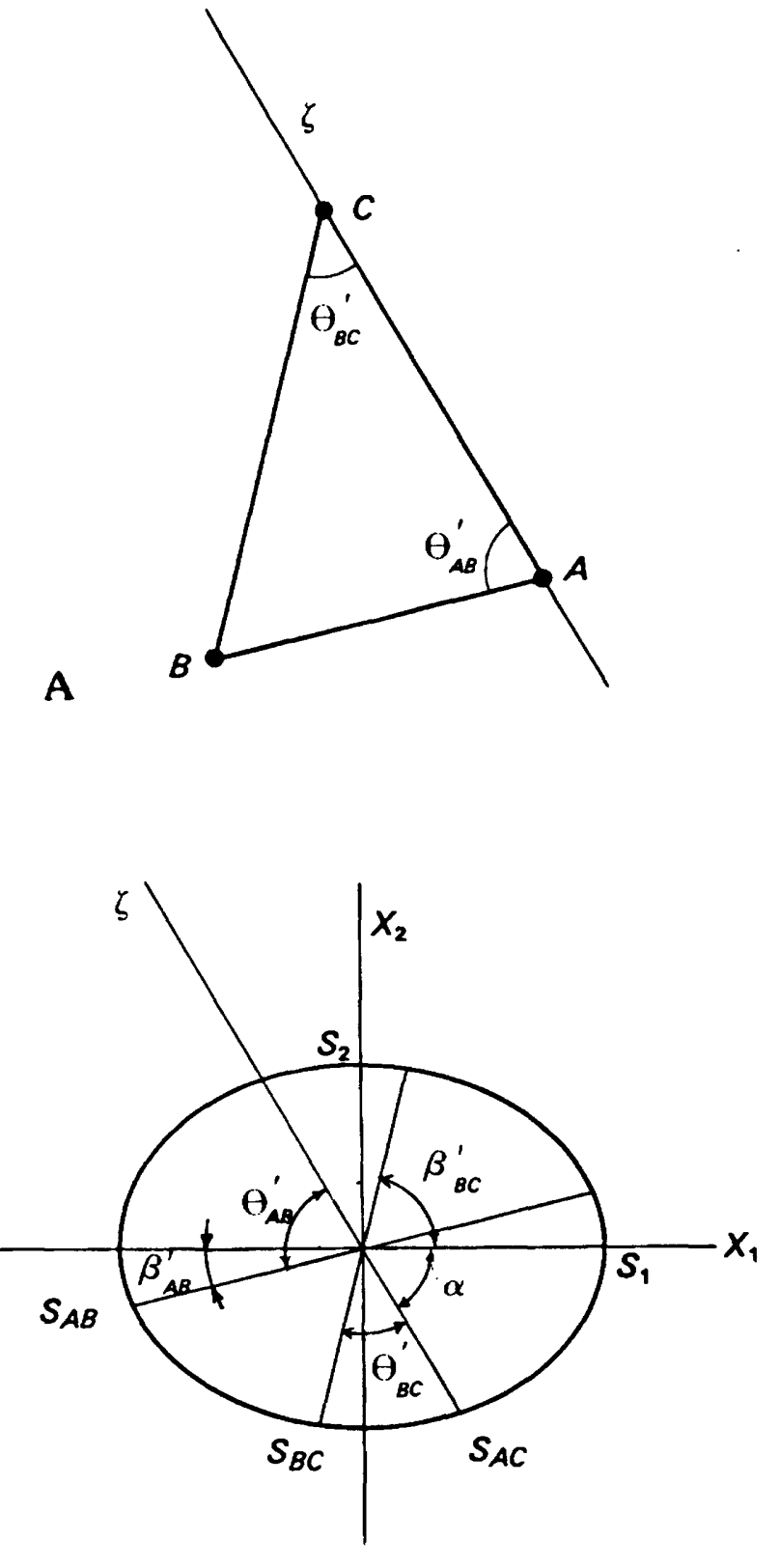

B

Figure B3. Diagram showing geometrical relationships between a deformed triangle and its stretch ellipse. (A) Triangle $A B C$ in its final state. Angle $\theta_{A B}^{\prime}$ is angle $C A B$; angle $\Theta_{B C}^{\prime}$ is angle $B C A$. (B) The stretch ellipse. $S_{1}$ and $S_{2}$ are the principal stretches and are parallel to the $x_{1}$ and $x_{2}$ coordinates. $S_{A B}, S_{A C}$, and $S_{B C}$ are the components of stretch parallel to lines $A B, A C$, and $B C$, respectively. The angle is $\alpha\left(=\beta_{A C}\right)$, the acute angle between line $A C$ and $x_{1} ; \beta_{A B}^{\prime}=\theta_{A B}^{\prime}-\alpha ; \beta_{B C}^{\prime}=\alpha+\theta_{B C}^{\prime}$.

Repeating these calculations for each triangle in its initial and final states and determining the differences gives four values of tilt and four values for the change in dip direction.

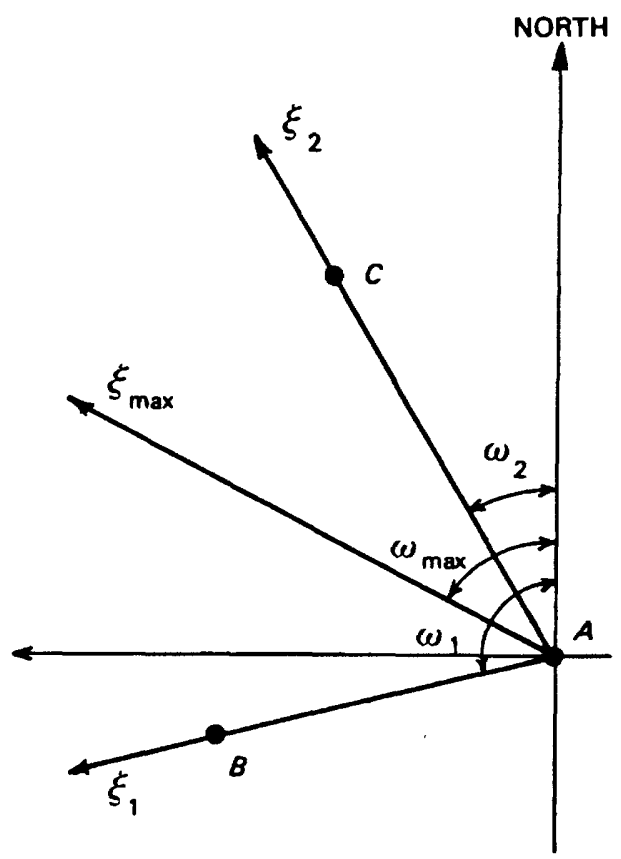

Figure B4. Diagram showing dip direction of triangle $A B C$, point $A$ has the highest elevation. The positive $x$ direction is due north. Line $A B$ parallels coordinate direction $\xi_{1}$, its bearing is $\omega_{1}$. Line $A C$ parallels coordinate direction $\xi_{2}$, and its bearing is $\omega_{2}$. The dip direction parallels coordinate direction $\xi_{\text {max }}$, and its bearing is $\omega_{\text {max. }}$.

Computation. - The data for computing the errors of closure, displacements, strains, and tilts are the slope distances and elevation differences between corners of the quadrilateral. The formulas for computing these quantities, given previously, were chosen to simplify the task of programming.

Separate programs are used for computing displacement or strain and tilt, and each program reads the data from files stored on a diskette. A file exists for each quadrilateral; each set of raw measurements in a file is identified by the date on which it was collected. Documentation and BASIC computer programs for creating the files and performing the computations are available from the U.S. Geological Survey (Johnson and Baum, 1987).

\section{Field Technique}

At each site selected for strain or displacement measurement, we drove four wooden stakes in the ground to mark the corners of a quadrilateral, and put a small finishing nail in the top of each stake (fig. B1). 
We used a steel tape to measure distances between nails, hooking the end of the tape on one nail and reading the tape at the center of each of the other nails. The elevation of the top of each stake was obtained by taking backsights with a precision level. The azimuth of a reference line (diagonal $A C$ ) was measured with a Brunton compass so that strain and displacement data could be oriented.

No provisions were made to determine rigid body rotations of the quadrilaterals; where such data are of interest, accurate measurement of the azimuth of a reference line would be needed each time the length and elevation measurements were repeated. If the azimuth were known, additional computations would determine the rotation of a line that becomes parallel to the principal stretch.

We encountered three major difficulties in using the quadrilateral method: (1) Some of the stakes became tilted, loose, or broken, either by animals or heavy winter snow. (2) Repetition of length measurements showed that measurement errors of $3 \mathrm{~mm}$ were common and that errors of 5-6 mm sometimes occurred. (3) Errors of 0.5 $\mathrm{mm}$ were fairly common in the elevation measurements, apparently because many stakes were tilted. However, errors were small in comparison to displacement.

In order to minimize the errors, we discounted results from stakes that were loose or greatly tilted. Also, we used the theory of quadrilaterals to detect errors of measurement of length.

We tried quadrilaterals of various shapes; however, most were approximately square (that is, equidimensional). Squares worked well because it was difficult to anticipate the direction of maximum strain at most locations on the landslide. The advantage of using a shape that is approximately square is that strain measurements are distributed throughout the four quadrants, whereas an elongate quadrilateral tends to concentrate strain measurements in two opposite quadrants.

Squares also worked well for displacement measurements. However, as quadrilaterals were distorted into diamond shapes, measurement errors increased. Thus, it was necessary to put new stakes in the ground from time to time to restore the original square shape of some of the quadrilaterals.

The quadrilaterals that we used ranged from 1.5 to $10 \mathrm{~m}$ in width, but quadrilaterals that were from 1.5 to 4 $\mathrm{m}$ wide seemed to work best for strain measurements. The larger quadrilaterals (from 6 to $10 \mathrm{~m}$ wide) were sensitive to inhomogeneous strain. Quadrilaterals smaller than $1.5 \mathrm{~m}$ would be too sensitive to measurement error.

Experience indicated that displacement measurements were needed more often, whereas strain measurements were needed less often than we made them. During June and July 1983, and May 1984, the quadrilaterals were measured once every two or three days. Displacements averaged a few millimeters per day in 1983 and a few centimeters per day in 1984. By measuring every few days, a discontinuous record of displacements was obtained. However, the strain accumulating from a few days of movement was often too small to measure.

In order to satisfactorily measure displacement and strain in 1985 , we measured the quadrilaterals once every three or four weeks and supplemented the quadrilaterals with three recording extensiometers along a flank of the landslide in order to obtain more nearly continuous displacement data. From the quadrilateral measurements, we computed the long-term (weeks or months) displacements at many points on the boundaries and long-term strains at points on the surface of the landslide. The combination of measurements used in 1985 worked well for our purposes, except that erroneous measurements of strains were more difficult to detect.

\section{Errors and Sensitivity}

Detection and distribution of errors.-When quadrilaterals were measured frequently (once every two to three days, or several times a day) many inaccurate data sets could be eliminated by inspection. Measurements that differed significantly from a series of otherwise constant values or a steady trend were regarded as inaccurate and were discarded. From the remaining sets of measurements, those having the smallest errors of closure were used for strain computations.

Errors of closure were computed by means of equation 1 , as an aid in detecting inaccurate data sets. A simple method for distributing the errors, described by Laurila (1983, p. 41-45), was tried. In order to apply this method, we assumed that the length of one side of each quadrilateral, $A B$, was known accurately; however, we had no independent check on the length of $A B$ or any other length. Thus, if $A B$ happened to be measured inaccurately, then using it to distribute the errors might make the adjusted measurements less accurate than the original measurements. Therefore, we decided to use the raw measurements, and to eliminate sets of measurements that had errors of closure larger than $0.3^{\circ}{ }^{2}$ By inspecting the raw measurements and checking

\footnotetext{
${ }^{2}$ By computing the error of closure for a square quadrilateral having sides exactly $2 \mathrm{~m}$ long, we found that an error of $6 \mathrm{~mm}$ in the measured length of one side caused an error of closure equal to approximately $0.3^{\circ}$.
} 
the magnitude of $w$, we eliminated data sets having closure errors larger than a few millimeters.

Sensitivity of measurements.-When we measured quadrilaterals and then remeasured them a few minutes later, we found that our measurements could differ by as much as $5-6 \mathrm{~mm}$, which is equivalent to a strain of 0.003 in a quadrilateral with sides of $2 \mathrm{~m}$ length. Errors of 5-6 $\mathrm{mm}$ occurred in 10-20 percent of our measurements. Consequently, the smallest strains that could be detected confidently by our measurements with a steel tape were 0.003 ( 0.3 percent strain). As a result, the smallest strain that could be computed with an error less than 10 percent was 0.030 (3.0 percent strain). We sometimes used measurements where the strains were less than 0.030 , especially if they were internally consistent and the orientations of the principal stretches for the four triangles were oriented in about the same direction.

The measurements were adequate for observing long-term strains. Strains of $+0.080(+8.0$ percent $)$ to $-0.180 \quad(-18.0$ percent $)$ accumulated at many quadrilaterals during weeks and months of landslide movement. Thus, long-term strains were large compared to errors in the measurements.

Because boundary displacements of many decimeters accumulated as a result of days or weeks of landslide movement, measurement errors were small enough to disregard when computing displacements.

\section{EXAMPLES OF QUADRILATERAL MEASUREMENTS}

In order to illustrate how quadrilaterals have been used in the field to measure displacement, strain, and tilt, several examples from the Aspen Grove landslide in central Utah are cited: (1) the measurement of displacement at a landslide flank (strike-slip fault), (2) the measurement of displacement at a landslide toe (thrust fault), (3) the measurement of tilt and strain on a ridge, and (4) the measurement of strain at a place that unexpectedly became a normal fault. Before describing the history of the quadrilateral sites, we briefly describe the landslide.

\section{The Aspen Grove Landslide}

The Aspen Grove landslide, on a northwest-facing, forested slope in Ephraim Canyon, central Utah (fig. B5), involves old landslide debris that consists of sandstone boulders in a sandy clay matrix. The slope angle of the landslide surface averages $11^{\circ}$ and locally ranges from $0^{\circ}$ to $31^{\circ}$. From drilling and mapping in the vicinity of the landslide, we infer that the landslide debris occupies a trough in the surface of the bedrock.

The landslide debris upslope from a road that crosses the lower part of the landslide (fig. B6) is probably less than $10 \mathrm{~m}$ thick. At boreholes B-1, B-2, and $\mathrm{B}-3$, in the upper part of the landslide, the debris is $6 \mathrm{~m}$ thick. Downslope from the lower road crossing, the debris may be as thick as $15-20 \mathrm{~m}$ beneath the large internal toe (between quadrilaterals Q-26 and Q-27, fig. B6).

The Aspen Grove landslide is $1 \mathrm{~km}$ long and its width changes gradually throughout its length. From the head (quadrilateral $\mathrm{Q}-1$, fig. B6) to the vicinity of B-1, the width is from 50 to $55 \mathrm{~m}$. Downslope from B-1, the width decreases to a minimum of $20 \mathrm{~m}$ near the $2340 \mathrm{~m}$ contour and then increases farther downslope to a maximum of $100 \mathrm{~m}$ on the internal toe. Downslope from the internal toe, the landslide is $70 \mathrm{~m}$ wide near quadrilateral Q-32, but beyond the edge of the mapped area, its width increases again to about $100 \mathrm{~m}$.

Sliding at Aspen Grove began late in May 1983 when a record snowpack containing from 75 to $100 \mathrm{~cm}$ of water melted in a few weeks. Discontinuous ground cracks marking the boundaries of the landslide were first discovered on May 31, 1983, and sliding continued for several weeks, until mid-July or early August. During this time, the landslide extended from the head at quadrilateral Q-1 (fig. B6) to the vicinity of quadrilaterals Q-8 and Q-29. The landslide was dormant from late summer 1983 until approximately mid-April 1984, when sliding was renewed in all parts of the landslide that had been active in 1983. Features at the surface of the landslide evolved dramatically. Many of the tension cracks in the head region opened wide, as the thin debris at the head slid downslope. A graben, near quadrilateral Q-13, and the flank ridge, at quadrilateral Q-2, enlarged. Flanks defined by en echelon cracks and fault segments in 1983 were defined by continuous strike-slip faults in 1984. The flanks of the landslide propagated farther downslope than in 1983. By the time we saw the landslide in mid-May, cracks had appeared at the 2,280 m contour on the internal toe. By the end of May, scattered cracks were visible downslope from the internal toe (near quadrilateral Q-32, fig. B6). In August 1984 , we observed a new shear zone that had started to form on the right flank ${ }^{3}$, between quadrilateral Q-2 and quadrilateral Q-13.

\footnotetext{
${ }^{3}$ The right flank is to the right of an observer standing at the crown and looking downslope. By this convention, right-lateral shearing occurs on the right flank.
} 


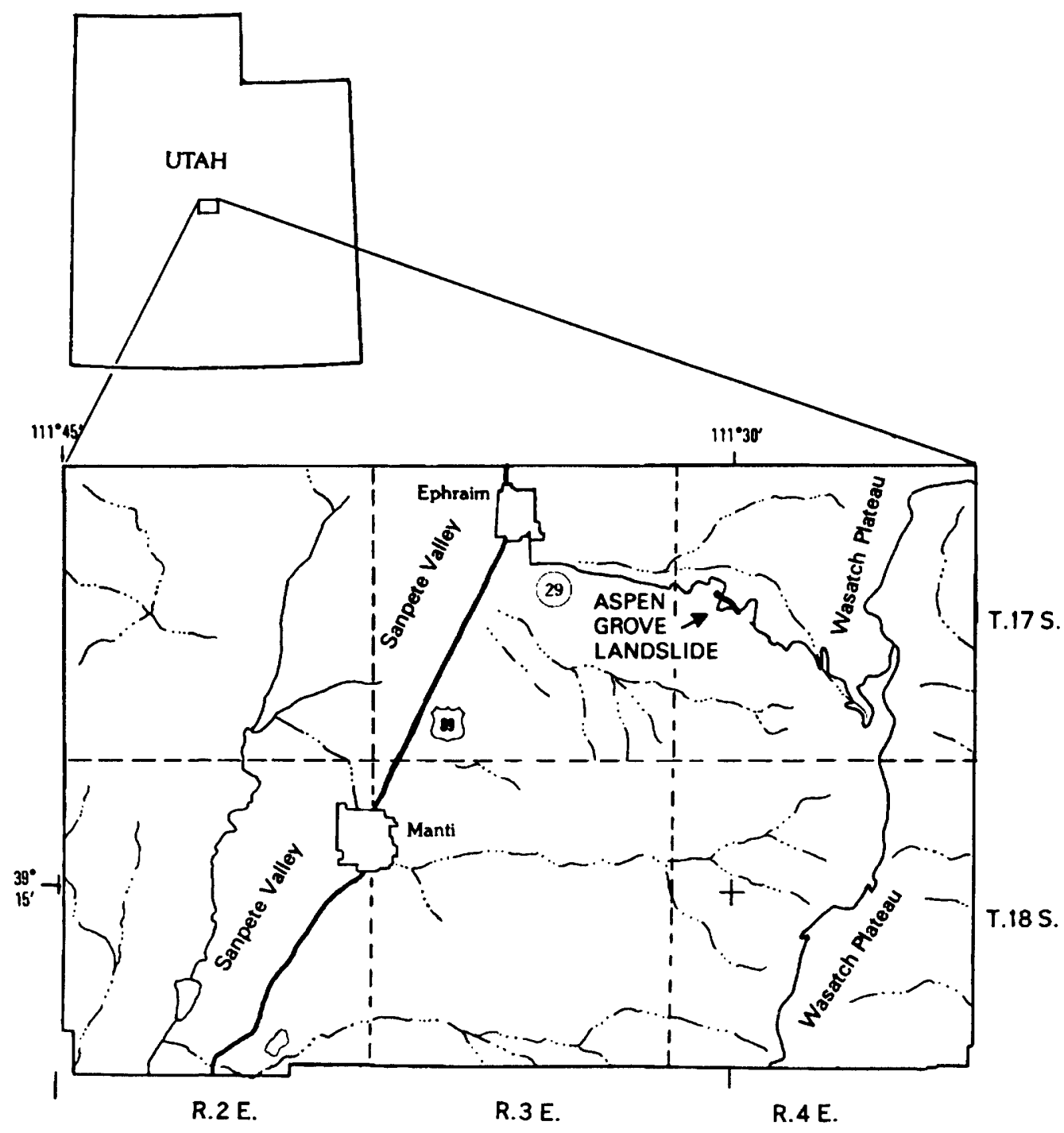

Figure B5. Map showing location of the Aspen Grove landslide, central Utah.

\section{Measurement of Displacement on a Landslide Flank}

The flanks of the Aspen Grove landslide were characterized by strike-slip faults or shear zones. The faults were from a few centimeters to a few decimeters wide, so that small quadrilaterals worked well to measure displacement on the faults and strain parallel to the faults. The installation and history of quadrilateral Q-2 is described as an example of using a quadrilateral to measure displacement on a landslide flank.

Quadrilateral Q-2 was installed on the right flank, in the upper one-third of the Aspen Grove landslide, on June 15, 1983 (fig. B6). It was primarily intended to provide a sensitive measure of displacement on the right flank. Also, the two stakes of Q-2 on moving ground could be used to measure one-dimensional strain adjacent to the strike-slip fault on the right flank.

A perspective sketch (fig. B7), based on a photograph, shows the site as it appeared on the day the stakes were installed. Two cracks marked the location of a right-lateral shear zone. The shear zone was parallel to the axis of a low ridge, from 50 to $80 \mathrm{~cm}$ high, and passed through the northeast flank of the ridge.

Small swales with axes parallel to the shear zone occurred on each side of the ridge. The one on the outer side of the ridge, on stationary ground, is shown in the foreground in figure B7. It was about $2 \mathrm{~m}$ wide and $1 \mathrm{~m}$ deep; it had a smooth, roughly semicircular profile. The swale on moving ground was subtle; it was marked by a small furrow at the boundary between the ridge and the 


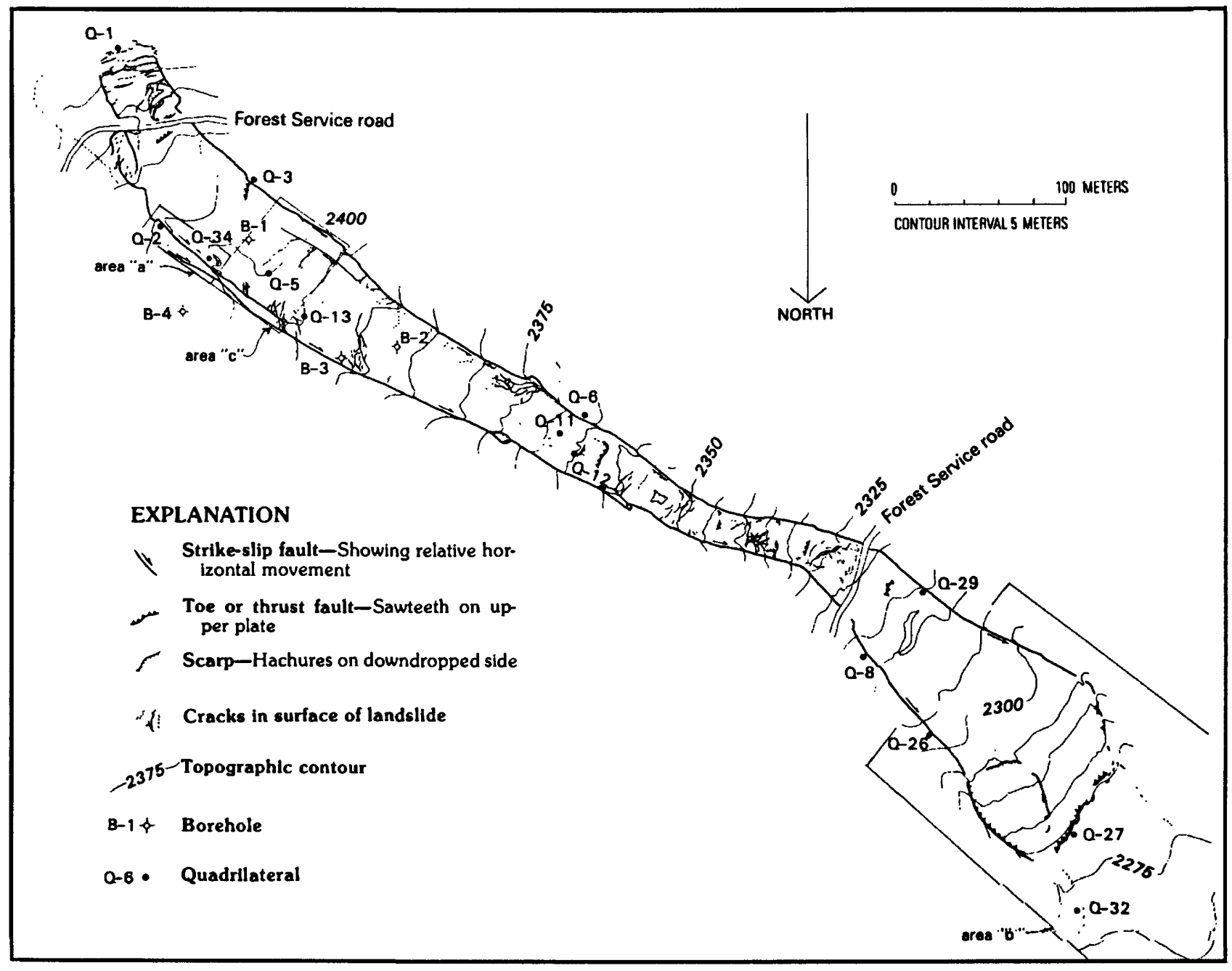

Figure B6. Map showing the Aspen Grove landslide, August 1984.

slightly arched, convex surface of the landslide. Twenty meters farther downslope, both swales became more prominent and the ridge became a conspicuous topographic feature.

Stakes $C$ and $D$ were placed on stationary ground northeast of the ridge so that line $D C$ was parallel to the shear zone, which had a trend of N. $41^{\circ}$ W. Stakes $A$ and $B$ were placed on the crest of the ridge, on moving ground, a few decimeters southeast of the shear zone (opposite stakes $C$ and $D$ ).

The size, orientation, and shape of the quadrilateral were determined mainly by the geometry of the site. The quadrilateral needed to be large enough to straddle the shear zone and allow clearance for the measuring tape to stretch between the tops of the stakes. Had stakes $A$ and $B$ been located off the crest of the ridge, clearance might have been a problem. The reference line (line $C D$, the line defined by stakes on stationary ground) was approximately parallel to the shear zone so that the largest component of displacement would be parallel to the reference line. This orientation was chosen for convenience in making the measurements and in orienting the displacement vectors. The trapezoidal shape was a result of trying to fit the quadrilateral to the site.

During part of June and July 1983, the quadrilateral was measured once every two or three days, and displacement on the shear zone was computed for the period from June 15 to August 4. Movement on the shear zone amounted to $14 \mathrm{~cm}$ between June 15 and July 10, when movement ended. The azimuth of the displacement was N. $49^{\circ}$ W., or $8^{\circ}$ counterclockwise from the trend of the shear zone. Thus, the stakes were displaced toward the center of the landslide, away from the shear zone. The quadrilateral functioned very well. The strike-slip displacements were much larger than the measurement errors.

Renewed movement began in the spring of 1984, and displacement of $2.2 \mathrm{~m}$, nearly parallel to the trend of the fault zone, occurred between August 4, 1983, and 


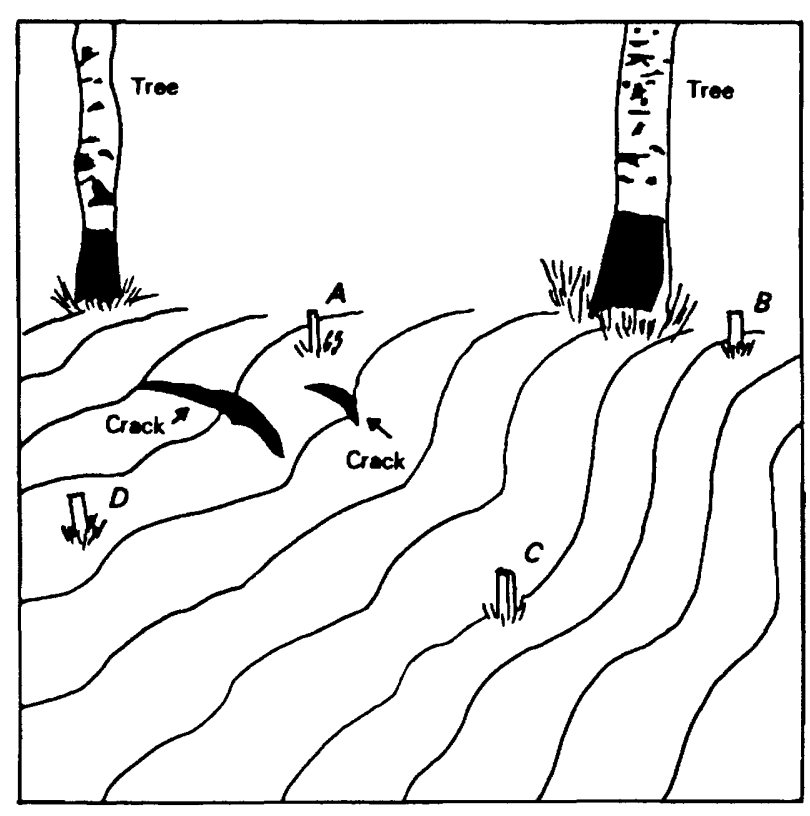

Figure B7. Sketch of the site of Q-2 (part of area "a", shown in fig. B6) made from photograph taken by R.W. Fleming on June 15,1983 . Ground surface depicted by means of serial profiles in perspective view.

May 23, 1984. As a result of the displacement, the shear zone defined by en echelon cracks in 1983 was replaced by a through-going fault in 1984 (fig. B8). Moist, lightbrown, slickensided clay was exposed at the ground surface on either side of the fault, and vegetation was disrupted in a strip, from 10 to $20 \mathrm{~cm}$ wide, along the fault.

Shortening of 1.2 percent occurred between stakes $A$ and $B$ on the low ridge within the landslide between August 1983 and May 23, 1984. Shortening was surprising because the maximum rate of displacement was occurring approximately $230 \mathrm{~m}$ downslope from Q-2, and we had measured progressively less displacement in several places between this point of maximum displacement and Q-2. Thus, we expected the strain at Q-2 to be extensional.

As a result of the movement during the spring of 1984 , stake $B$ had moved into a position where the tape was deflected by the ground surface when measuring between stake $B$ and stake $C$ or $D$. Therefore, the movement of stake $B$ was overestimated in our calculations. No action was taken to correct this situation during 1984, because we were able to measure to point $A$ without difficulty.

The landslide was active through June and July and stopped moving sometime during August 1984. We measured Q-2 once every two or three days between May 23 and June 7, and once on August 3. Between May 23 and August 3,1.6 m of displacement occurred on the fault.
Displacement was oriented $11^{\circ}$ counterclockwise from the trace of the fault and plunged only $1.5^{\circ}$. The shallow plunge was interesting because one might expect the movement to be roughly parallel to the ground surface, which sloped $10^{\circ}$. The nonzero component of displacement of stakes normal to the fault, toward the center of the landslide, was also interesting because we observed no evidence of dilation near the fault. Both of these, though, might reflect a secondary flow of the landslide debris, which we associate with the construction of lateral ridges.

By April 1985, quadrilateral Q-2 had been deformed into a diamond-shaped figure. Therefore, after measuring the distances between all of the stakes, stakes $A$ and $B$ were removed and replaced with new stakes in positions that were across the shear zone and opposite stakes $C$ and $D$.

During the period that quadrilateral Q-2 was in use, the site changed. The shear zone evolved from a set of en echelon cracks to a through-going strike-slip fault.

The quadrilateral measured displacement of several meters, with sensitivity of several millimeters. Even though the quadrilateral was small, $2 \mathrm{~m}$ by $2 \mathrm{~m}$, it was able to measure displacements amounting to a few meters before stakes $A$ and $B$ had to be replaced in order to restore the original shape of the quadrilateral.

\section{Measurement of Displacement at a Landslide Toe}

In May 1984, we observed that the Aspen Grove landslide was enlarging distally. In 1983, it had terminated a few tens of meters below the lower road crossing (fig. B6). In 1984, cracks were appearing farther downslope, toward a large internal toe of the landslide that had formed during a previous episode of movement (near quadrilateral Q-27, fig. B6). We expected the internal toe to be reactivated and become the toe of the modern Aspen Grove landslide; we wanted to observe the early stages of movement as the toe became reactivated. Quadrilateral Q-27 was installed about halfway across the width of the toe on May 18, 1984, in order to accomplish this.

The internal toe was one of the most conspicuous features of the landslide surface (fig. B9A). The slope angle of the profile of the distal end of the toe was about $24^{\circ}$, and the angle gradually reduced to $16^{\circ}$ about $40 \mathrm{~m}$ upslope (fig. B9B). The toe was about $7 \mathrm{~m}$ high, and its maximum width was about $100 \mathrm{~m}$. However, the landslide was narrower upslope from the toe (fig. B6).

A site for a quadrilateral midway across the toe was chosen in an area relatively clear of vegetation that would interfere with measurement. Movement was expected to be greatest in this area; therefore, it was the optimum 

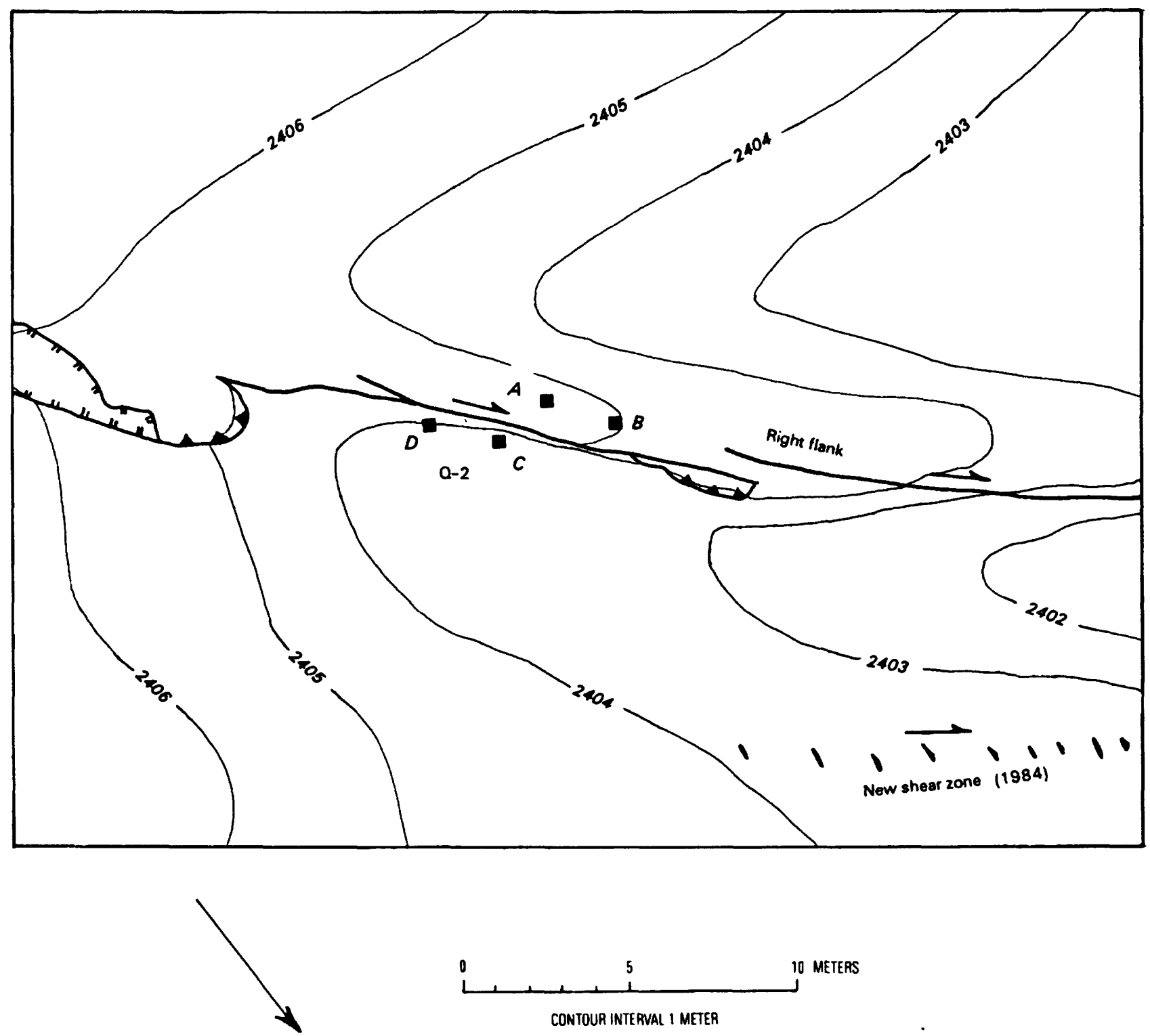

NORTH

EXPLANATION

Strike-slip fault-Showing relative horizontal movement

${ }_{2402}-$ Topographic contour

Thrust faul- - Sawteeth

on upper plate

A Stake at corner of quadrilateral

\section{Narrow cracks in surface
of landslide \\ Wide cracks in surface of landslide}

Q-2 Quadrilateral

Figure B8. Map showing part of the Aspen Grove landslide in vicinity of quadrilateral Q-2 during August 1984 (part of area "a", shown in fig. B6). 

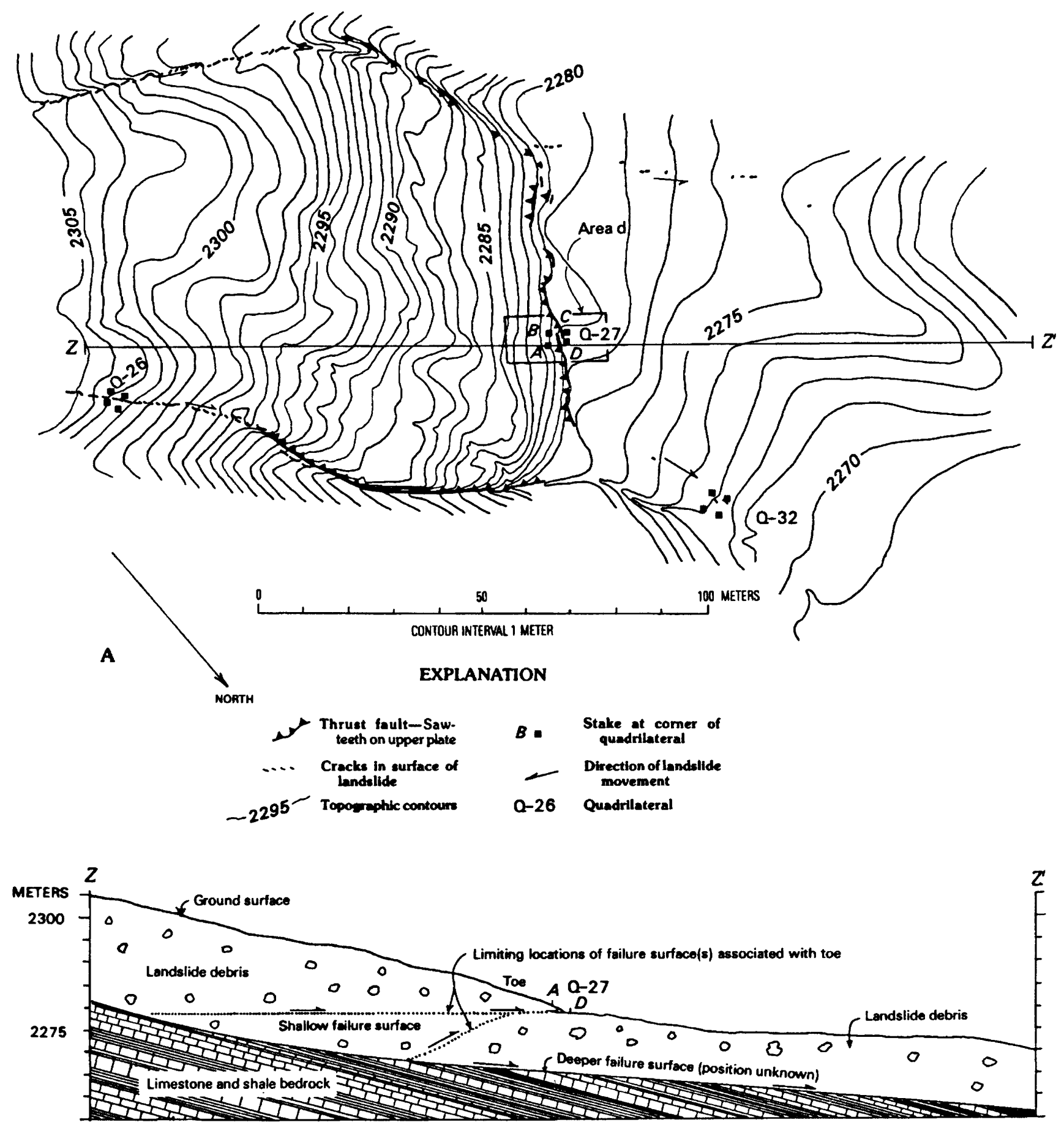

B

Figure B9. Map and cross section showing internal toe of the Aspen Grove landslide (area "b", shown in fig. 6). (A) Map view, August 1984. Landslide movement is from left to right. (B) Cross section Z-Z'. Dotted lines show locations of two possible slip surfaces.

place to detect small movements. Also, the toe was well defined topographically near its middle, so it seemed possible to estimate within a meter or two where the failure surface would intersect the ground surface.

The quadrilateral was oblong, from 2.2 to $2.8 \mathrm{~m}$ wide and $4.4 \mathrm{~m}$ long, and its long dimension was parallel to the axis of the landslide. Line $C D$ was installed on gently sloping ground, downslope from the toe (fig. B9). Points $C$ and $D$ were a meter downslope from where the thrust was expected to intersect the ground surface. We 
tried to make line $C D$ parallel to the local trend of the toe, so that motion would be approximately perpendicular to line $C D$. Points $A$ and $B$ were $4.3 \mathrm{~m}$ upslope from line $C D$, and were $1 \mathrm{~m}$ higher in elevation than stakes $C$ and $D$.

Within the quadrilateral, the ground surface sloped gently (a few degrees) for $1 \mathrm{~m}$ upslope from stakes $C$ and $D$. The slope then increased abruptly to $20^{\circ}$. The slope was relatively smooth, but pebbles, cobbles, and small undulations made the slope locally rough.

In order to document differential movement occurring in the toe, we measured Q-27 every few days from May 18 to June 6, 1984. The computed displacements for stake $A$ are shown in figure B10. Although we measured displacements of $6 \mathrm{~cm}$ between May 18 and June 2, no physical changes could be observed in the site.

When we returned to the site on June 6 , we observed a band of cracked soil on the face of the toe, just northeast of line $A D$. The displacement between May 18 and June 6 was $9 \mathrm{~cm}$. We do not know how much movement occurred in the toe before measurements were started at Q-27, but we do know that displacement of at least 6 to $9 \mathrm{~cm}$ was needed before the ground cracks became visible.

In August 1984, the cracks observed in June were no longer visible, but other thrust features appeared along the toe. Three branches of the thrust were observed and mapped within the boundaries of the quadrilateral (fig. B11). These changes were associated with $22 \mathrm{~cm}$ of displacement between May 18 and August 4, 1984.
Points $A$ and $B$, which were on the toe upslope from the thrust features, moved approximately parallel to the axis of the landslide. During May 1984, displacement of point $A$ was nearly horizontal. The ground surface of the landslide below Q-27 slopes about $7^{\circ}$, so the displacement at Q-27 has an upward component relative to the ground surface. Later displacements, occurring between June 6 and August 4, had a vertical upward component (fig. B10).

These movements were relative to stakes $C$ and $D$, which themselves were moving on a landslide element that was downslope from the internal toe. Thus, the magnitude and direction of movement of stakes $A$ and $B$ relative to nonmoving ground is unknown.

\section{Measurement of Strain and Tilt on a Ridge}

In June 1984, it was observed that the ridge near Q-2, on the right flank of the landslide, was deforming. Q-2 was at the upslope end of the ridge. Most evidence for growth of the ridge was 15 to $20 \mathrm{~m}$ farther downslope. Thus, stakes were installed there to measure and document the deformation that was occurring. Several quadrilaterals were installed on the ridge, one of which $(\mathrm{Q}-34)$ is described here.

In 1983, very few cracks were present within the boundaries of the Aspen Grove landslide. On June 2, 1984, near the beginning of the second season of movement, cracks were observed in the crest of the small ridge on the right flank of the landslide, near Q-2. Large tension cracks, oblique to the axis of the ridge, were

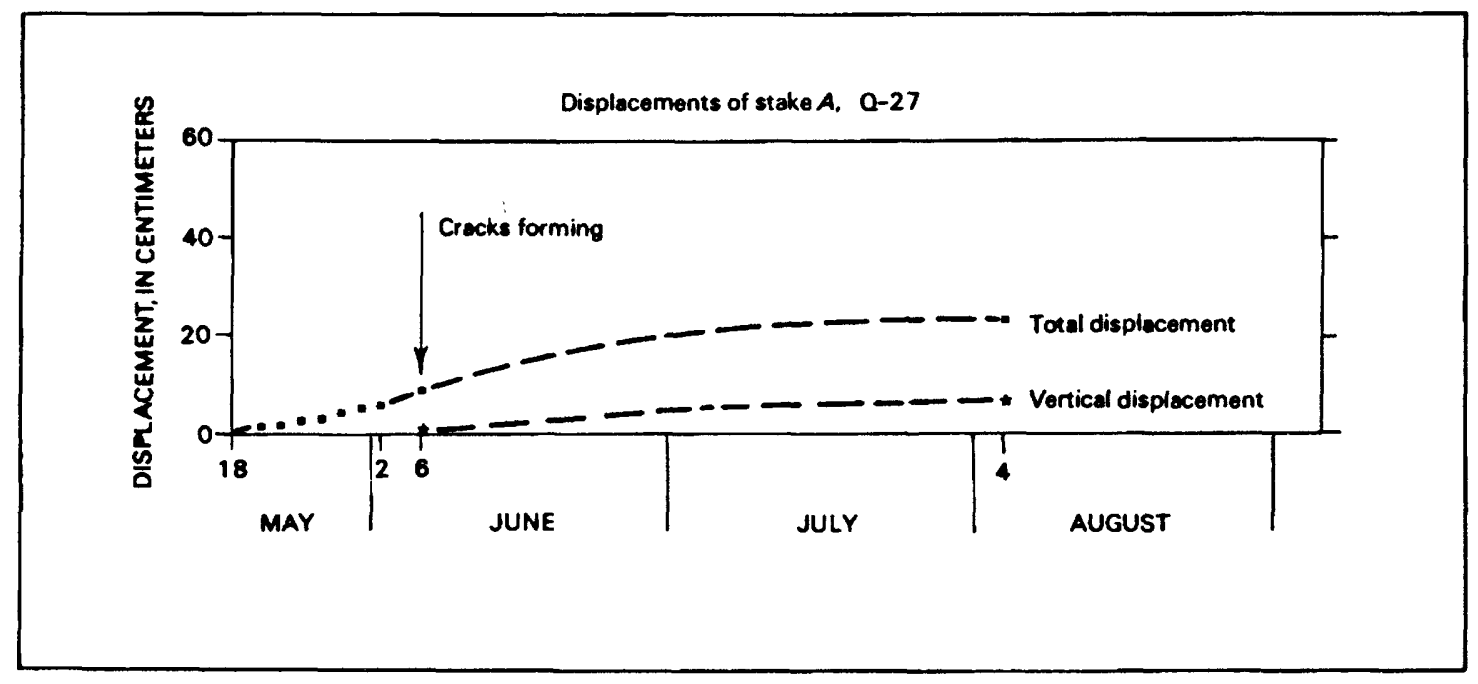

Figure B10. Graph showing displacements of stake $A$ at Q-27 from May 18 to August 4, 1984. 

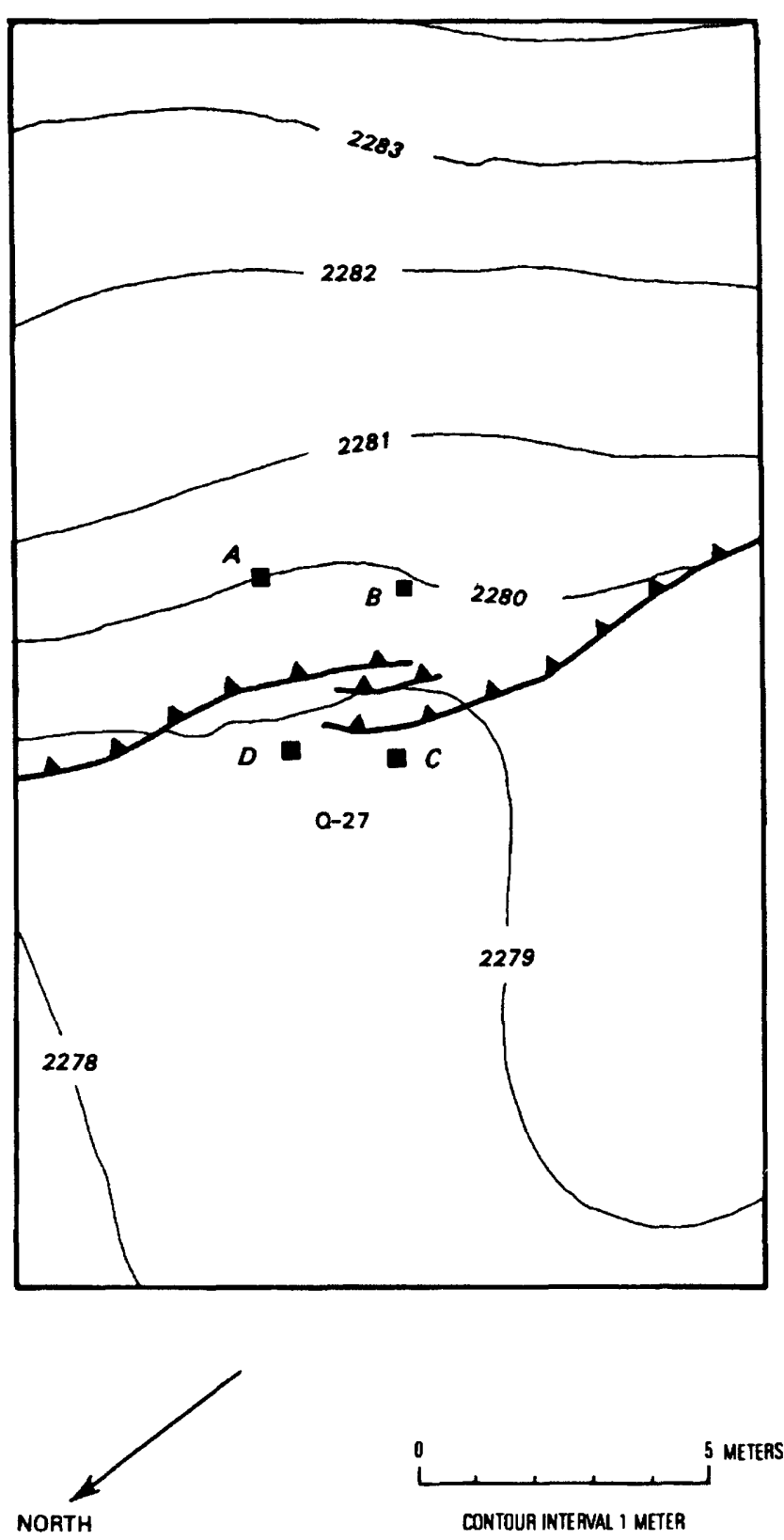

EXPLANATION
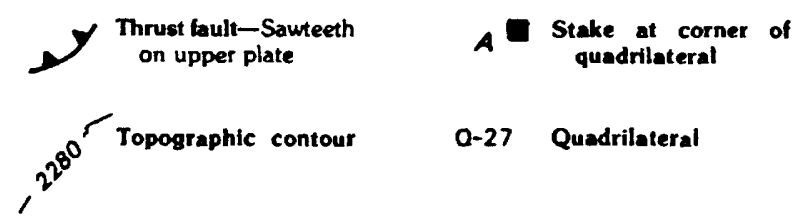

Figure B11. Enlarged view of area " $d$ ", shown in figure B9. Three thrust faults were noted within the boundaries of quadrilateral Q-27 in August 1984. observed at several places along the ridge crest. A fallen tree trunk lying on the south flank of the ridge had been lifted out of a depression it had formed in the ground surface.

The ridge itself was approximately $1-1.2 \mathrm{~m}$ high, 3 $\mathrm{m}$ wide, and $20 \mathrm{~m}$ long (fig. B6; fig. B12). In cross section, the ridge was rounded and slightly asymmetric. The north side of the ridge, which was parallel to the strike-slip fault, was steeper and higher than the south side of the ridge. The surface of the ridge was covered with boulders and had a thin layer of top soil.

Quadrilateral Q-34 was one of several points of measurement intended to document the growth and deformation of the ridge. One longitudinal and two transverse lines of stakes were surveyed on the ridge and across to stable ground. Also, two quadrilaterals were placed on different parts of the ridge. Quadrilateral Q-34 was intended to monitor a simple, relatively smooth section of the inside flank of the ridge. Two of the stakes, $C$ and $D$, were also part of a transverse stake line across the ridge. The transverse line provided data on ridge growth, and Q-34 provided data for computation of strain and tilt. Stakes $A$ and $B$ also provided a check on the results from stakes $C$ and $D$. We did not assume that growth of a ridge is two-dimensional.

Stakes $A$ and $D$ were installed near the crest of the ridge so that line $A D$ was nearly parallel to the axis of the ridge. Stakes $B$ and $C$ were installed downslope from stakes $A$ and $D$, near the base of the south side of the ridge, so that the four stakes defined the corners of a trapezoid (fig. B12). The quadrilateral was $3.3 \mathrm{~m}$ long and $2.6 \mathrm{~m}$ wide, and side $A D$ was $0.5 \mathrm{~m}$ higher than side $B C$.

Measurements were made on June 2, June 5, June 7, and August 3, 1984. Strain and tilt from June 2 to June 7 were small, and displacement along the right flank at Q-2 was only $0.15 \mathrm{~m}$. However, the magnitudes and directions of the strains were consistent among the four triangles in the quadrilateral. The maximum principal strain had a small positive value and was oriented toward the west or northwest. The minor principal strain indicated small amounts of shortening or elongation. Minor amounts of tilt, oriented toward the south, also occurred.

Considerably more deformation had occurred at Q-34 by August 3. The ridge was displaced $0.68 \mathrm{~m}$ between June 7 and August 3 (measured at Q-2), making a total displacement of $0.83 \mathrm{~m}$ since measurements started on June 2 . The major principal strain at Q-34 for the period June 2 to August 3 was oriented toward the west-northwest and was between +1.3 and +2.5 percent (table B1). The minor principal strain was from -0.3 to -0.6 percent. Continued tilting toward the south-southwest resulted in the southwest side of the ridge being $1.0-1.5^{\circ}$ steeper than it had been 


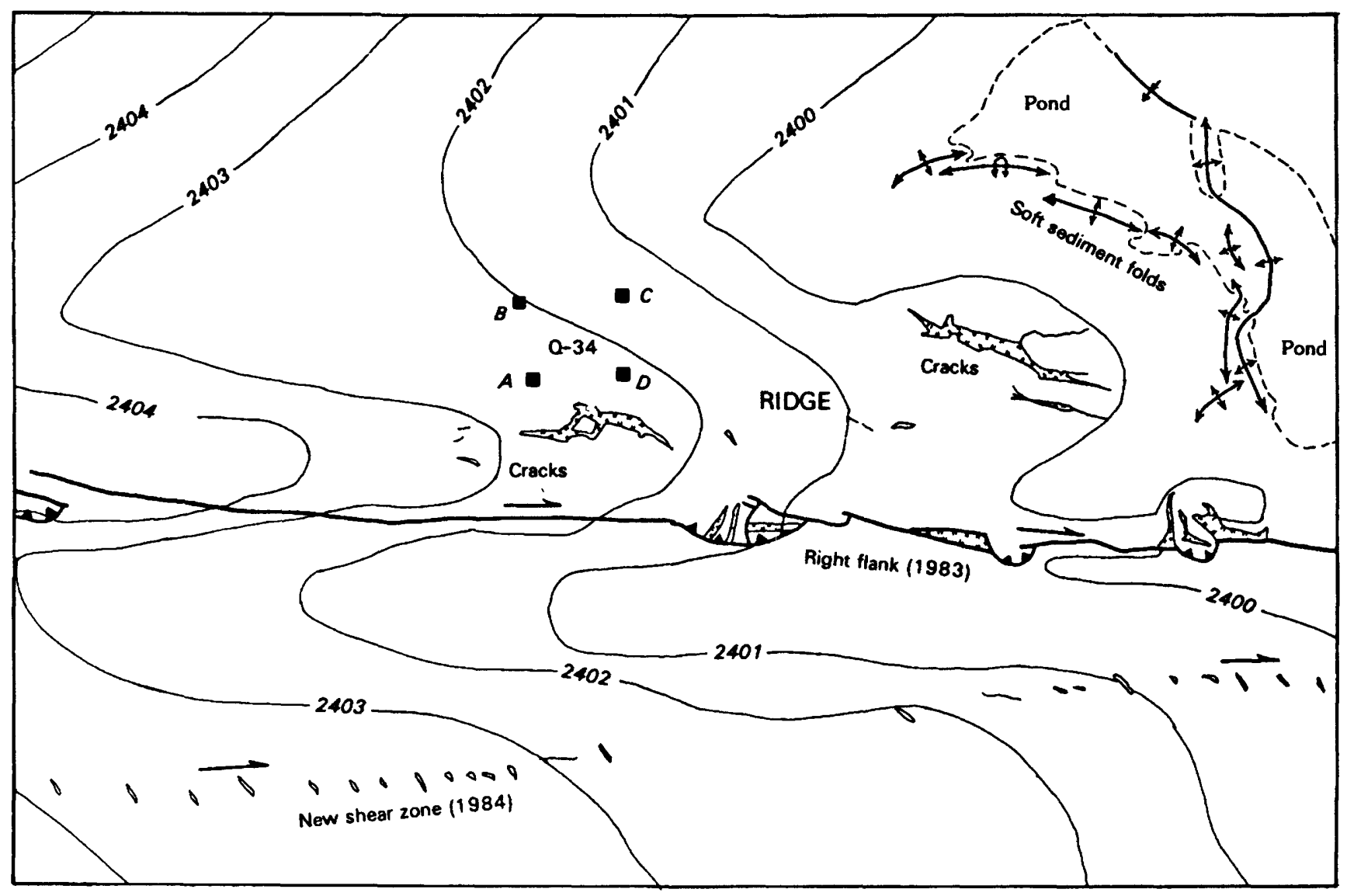

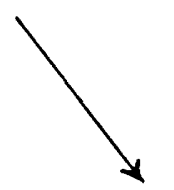

NORTH

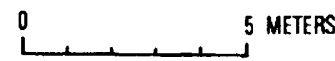

CONTOUR INTERVAL I METER

EXPLANATION

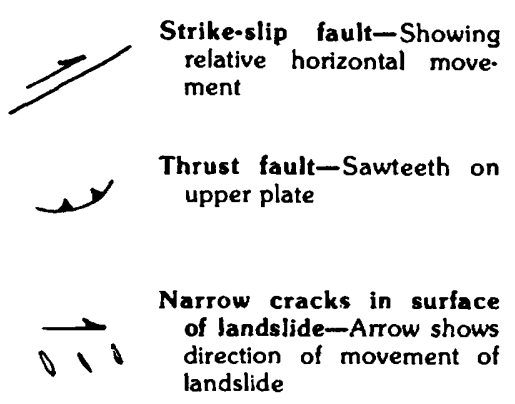

Wide cracks in surface of landslide

Anticline-Showing direction of plunge

Overturned, doubly plunging anticline

Monocline

Figure B12. Map showing ridge on the right flank of the Aspen Grove landslide (part of area "a", shown in fig. B6) (August 1984). Quadrilateral Q-34 was located on the southwest side of the ridge, on upper part of the landslide.

on June 2 (fig. B13). The site of the quadrilateral looked about the same as it had before, except that the cracks just upslope from Q-34 were slightly wider than they had been on June 2 .
During 1985, deformation of the ridge continued. The principal strains for the period June 2, 1984 to August 2, 1985, indicate that elongation in a west or west-northwest direction continued. A small amount of 
Table B1. Principal strains at Q-34

\begin{tabular}{|c|c|c|c|c|c|}
\hline $\begin{array}{l}\text { Beginning } \\
\text { Date }\end{array}$ & $\begin{array}{l}\text { Final } \\
\text { Date }\end{array}$ & Triangle & $\begin{array}{c}\text { Major } \\
\text { Principal } \\
\text { Strain } \\
\text { (percent) }\end{array}$ & $\begin{array}{c}\text { Az1muth - Major } \\
\text { Principal } \\
\text { Strain }\end{array}$ & $\begin{array}{l}\text { Minor } \\
\text { Principal } \\
\text { Strain } \\
\text { (percent) }\end{array}$ \\
\hline $6-2-84$ & $8-3-84$ & $\begin{array}{l}A B C \\
B C D \\
C D A \\
D A B\end{array}$ & $\begin{array}{l}+1.58 \\
+1.30 \\
+2.31 \\
+2.51\end{array}$ & $\begin{array}{l}\text { N. } 81^{\circ} \mathrm{W} . \\
\text { N. } 63^{\circ} \mathrm{W} . \\
\text { N. } 62^{\circ} \mathrm{W} . \\
\text { N. } 73^{\circ} \mathrm{W} .\end{array}$ & $\begin{array}{l}-0.76 \\
-0.32 \\
-0.33 \\
-0.55\end{array}$ \\
\hline $6-2-84$ & $8-2-85$ & $\begin{array}{l}A B C \\
B C D \\
C D A \\
D A B\end{array}$ & $\begin{array}{l}+5.91 \\
+6.82 \\
+4.62 \\
+3.74\end{array}$ & $\begin{array}{l}\text { N. } 73^{\circ} \mathrm{W} . \\
\text { N. } 89^{\circ} \mathrm{W} . \\
\text { N. } 86^{\circ} \mathrm{W} . \\
\text { N. } 66^{\circ} \mathrm{W} .\end{array}$ & $\begin{array}{l}-1.91 \\
+0.48 \\
+0.82 \\
-0.91\end{array}$ \\
\hline
\end{tabular}

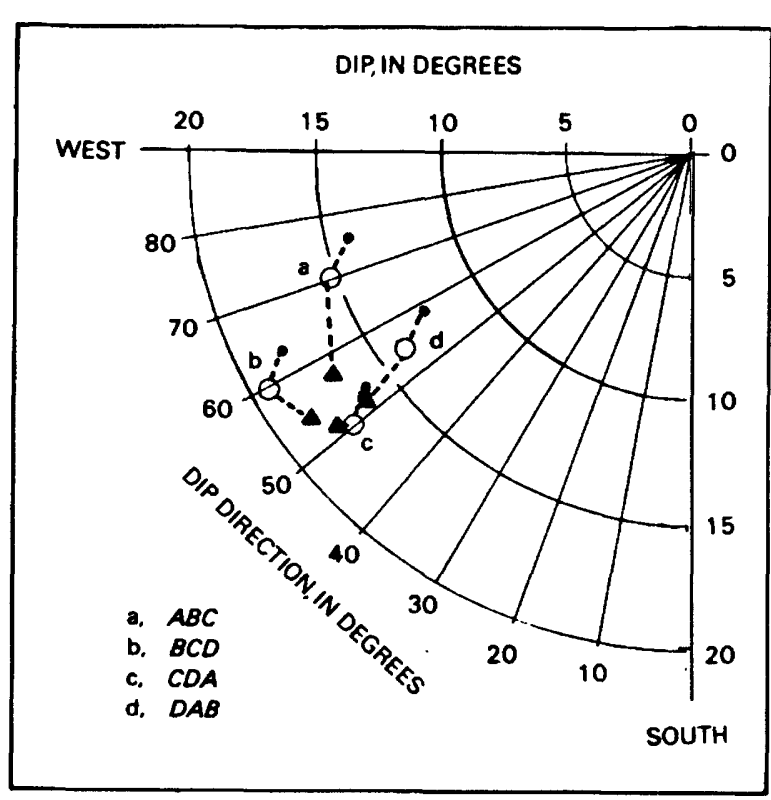

Figure B13. Polar plot showing attitude (dip and dip directions) of the four triangles in quadrilateral Q-34. Solid dots, attitudes on June 2, 1984; open circles, attitudes on August 3, 1984; and solid triangles, attitudes on August 2, 1985.

shortening occurred in triangles $A B C$ and $D A B$ and elongation occurred in triangles $B C D$ and $C D A$ in a north or north-northeast direction (table B1). Tilt increased at three of the triangles and decreased slightly at one (fig. B13). The 1985 deformation resulted from 1.36 $\mathrm{m}$ of displacement on the old flank fault $(2.19 \mathrm{~m}$ for 1984 and 1985 combined) and $1.95 \mathrm{~m}$ of displacement on the new flank fault.

The measurements of the quadrilateral showed that the ridge was, in fact, growing in height while the landslide was moving during 1984 and 1985. Steepening of the side of the ridge, as documented by the increasing tilt of the quadrilateral, showed that the ridge was growing in height relative to the neighboring ground.
Although shortening of the quadrilateral perpendicular to the ridge axis would have produced similar results, the leveling data show that the vertical distance between line $A D$ and line $B C$ actually increased. For example, the height differences between stakes $A$ and $B$ increased from $0.48 \mathrm{~m}$ on June 2, 1984 to $0.54 \mathrm{~m}$ on August 4, 1984 .

The ridge elongated approximately parallel to its axis. Deformation perpendicular to the axis of the ridge was small, and shortening occurred in some triangles but elongation occurred in others. Area strain was positive (increasing area) throughout the period of activity; however, no tension cracks formed within the quadrilateral. Positive area strain is normally associated with thinning of the landslide debris. However, positive area strain in Q-34 was associated with growth in the height of the ridge.

\section{Measurement of Strain and Tilt in an Area of Developing Normal Faults Within the Landslide}

During early June 1983, only a few cracks were the sole evidence of deformation anywhere within the boundaries of the Aspen Grove landslide. Quadrilateral Q-5 was set on a topographic high point near the axis (midway between the two flanks) of the landslide, at a high point along a prominent change in slope. East of $Q-5$, the surface of the landslide had a backslope of a few degrees toward the northeast (fig. B6). West of Q-5, the surface of the landslide sloped toward the northwest, roughly parallel to the direction of sliding, but the ground was locally steepened.

We expected purely extensional strains at Q-5 because the most rapidly moving part of the landslide was $170 \mathrm{~m}$ downslope from $\mathrm{Q}-5$. Although we wanted to observe these strains, we were perhaps more interested in monitoring changes in what was initially a high point in the surface of the landslide. 
Quadrilateral Q-5 was $1.8 \mathrm{~m}$ wide, $2 \mathrm{~m}$ long, and roughly rectangular. The long dimension of the quadrilateral was oriented N. $50^{\circ}$ E. and the short dimension was oriented N. $30^{\circ} \mathrm{W}$. Thus, the sides of the quadrilateral were slightly oblique to the axis of the landslide, which was oriented N. $55^{\circ}$ W. The quadrilateral sloped gently (about $8^{\circ}$ ) toward the northnorthwest.

During 1983, quadrilateral Q-5 remained unchanged. The computed strains were of the same size as those that would result from the expected errors in the measurements (table B2) and the principal strains showed inconsistent orientations among the four triangles. Thus, any deformation that occurred during 1983 was too small to be detected by our measurements.

During 1984, it was apparent that Q-5 no longer stood on the high point of the landslide. The highest point in the area was now upslope from Q-5 and closer to the left flank (fig. B14). Tilt of quadrilateral Q-5 increased from August 4, 1983 to May 23, 1984. From May 23 to August 3,1984, the slope of line $A B$ increased while the slope of line $A C$ remained unchanged and the slope of line $A D$ decreased. Thus, the quadrilateral sloped from $10^{\circ}$ to $11^{\circ}$ toward the north-northwest by August 3, 1984 .

Strains were relatively small in 1984 and the principal strains were difficult to interpret; however, the deformation can be understood by looking at the relative motions of the four stakes (table B2). For the period from August 4, 1983 to May 23, 1984, the strains in individual stake lines show that stakes $A$ and $C$ moved toward stake $B$. Between May 23 and August 3, 1984, stakes $A, C$, and $D$ maintained their positions relative to one another, but stake $B$ moved away from the other three.

In 1985, the difference in topographic form became even more pronounced than it had been in 1984 (fig. B15). Tension cracks that had been noted near the left flank in 1984 appeared upslope from and within quadrilateral Q-5. By this time, Q-5 had changed from a gently sloping quadrilateral on a high point to a steeply sloping quadrilateral downslope from a high point. The quadrilateral sloped from $11^{\circ}$ to $12^{\circ}$ toward the northwest or north-northwest. Line $A B$ continued to steepen during 1985 , while lines $A C$ and $A D$ became flatter.
During the period from August 3, 1984 to August 4,1985 , the major principal strain was oriented between west and northwest, or roughly parallel to line $B D$. The minor principal strain indicated a small amount of contraction normal to that direction. As in the latter part of 1984, the relative motions of individual stakes indicated that triangle $A C D$ remained relatively undeformed, while stake $B$ moved away from it (table B2). Such motion is consistent with the appearance of cracks between stake $B$ and triangle $A C D$ during 1985 .

In 1986, cracks that appeared during 1985 developed into a normal fault (fig. B16) that dropped stake $B 13 \mathrm{~cm}$ relative to stake $A$ between August 2, 1985 and September 12, 1986. The fault scarp appeared to be between 10 and $15 \mathrm{~cm}$ high and nearly vertical. Horizontal displacement of stake $B$ relative to line $A D$ amounted to only one centimeter during the same period; thus, movement was roughly parallel to the fault surface exposed in the scarp. Stakes $C$ and $D$ moved upward relative to stake $A$ so that triangle $A C D$ was relatively flat in September 1986.

Deformation at quadrilateral Q-5 was surprising. While the first few meters of movement occurred, the quadrilateral deformed very little but steepened as it apparently moved off a high point in the slip surface of the landslide. Crack-like deformation began during 1984 as stake $B$ moved away from triangle $A C D$, well before cracks appeared within the quadrilateral during 1985. What appeared to be simple tilting of the quadrilateral during 1984 and 1985, apparently was a precursor of the movement on the normal fault that occurred in 1986. Thus, had we recognized the style of deformation evident in the data, we could have predicted the formation of a normal fault passing through Q-5 long before the fault could be observed in the field.

\section{DISCUSSION AND CONCLUSION}

We have described a method for measuring the displacements, strains, and tilts at the surface of a landslide and have illustrated the ficld technique by means of examples.

The method is practical and can be easily done along with field mapping and other data-collection activities. The field technique is simple and the required

Table B2. Strains in Quadrilateral Q-5

\begin{tabular}{|c|c|c|c|c|c|c|c|}
\hline \multirow{2}{*}{$\begin{array}{l}\text { Beginning } \\
\text { Date }\end{array}$} & \multirow{2}{*}{$\begin{array}{l}\text { Final } \\
\text { Date }\end{array}$} & \multicolumn{6}{|c|}{ Strain in lines (percent) } \\
\hline & & $A B$ & $B C$ & $C D$ & $D A$ & $A C$ & $B D$ \\
\hline $\begin{array}{l}6-16-83 \\
8-4-83 \\
5-23-84 \\
8-3-84\end{array}$ & $\begin{array}{l}8-4-83 \\
5-23-84 \\
8-3-84 \\
8-2-85\end{array}$ & $\begin{array}{r}0.0 \\
-1.4 \\
+0.3 \\
+4.5\end{array}$ & $\begin{array}{l}+0.1 \\
-0.7 \\
+0.3 \\
+1.1\end{array}$ & $\begin{array}{l}+0.1 \\
+0.9 \\
-0.2 \\
-0.1\end{array}$ & $\begin{array}{l}-0.2 \\
+0.7 \\
+0.2 \\
-0.1\end{array}$ & $\begin{array}{l}-0.1 \\
-0.3 \\
-0.3 \\
-0.5\end{array}$ & $\begin{array}{r}+0.1 \\
0.0 \\
+0.6 \\
+3.5\end{array}$ \\
\hline
\end{tabular}



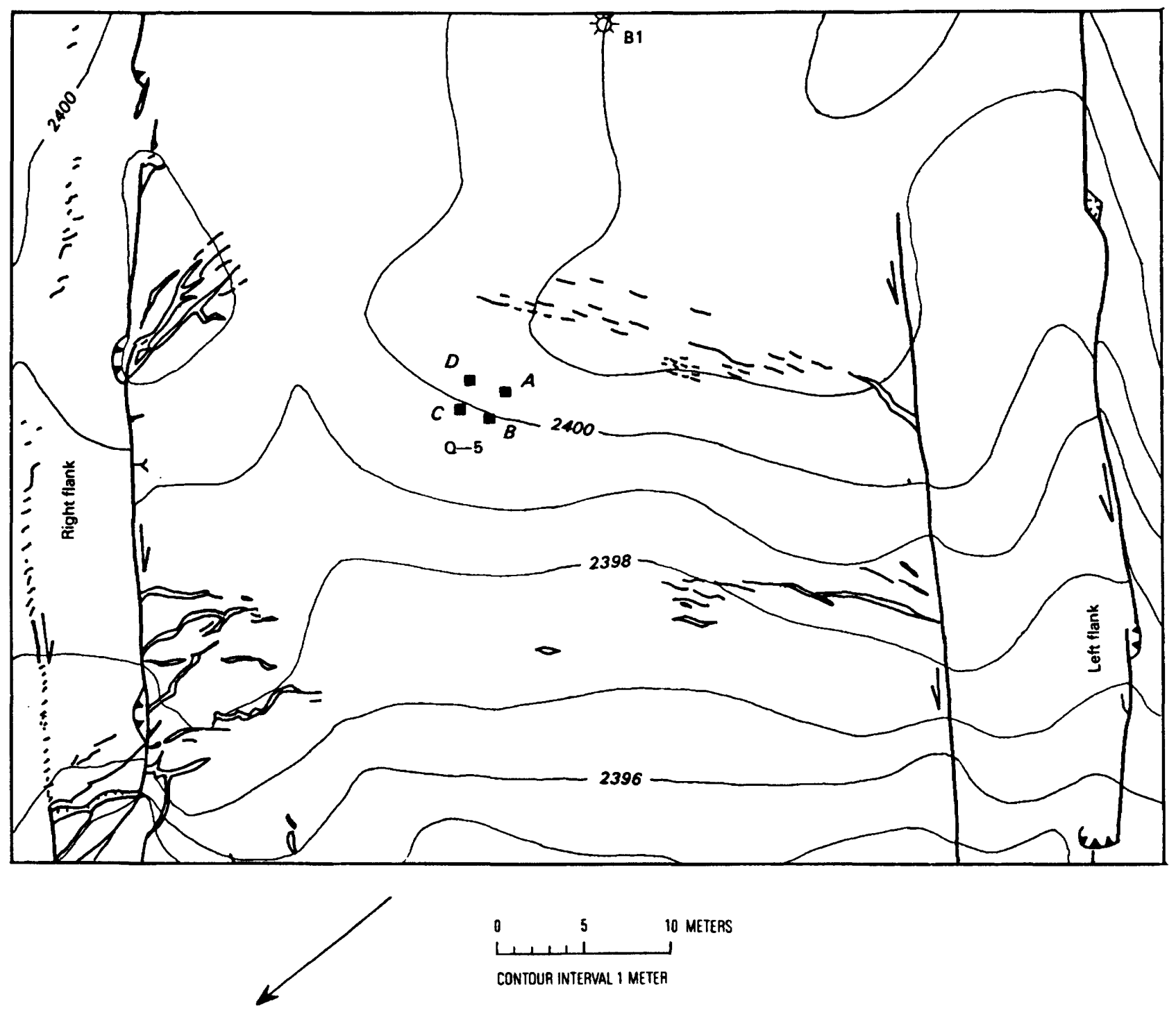

NORTH

EXPLANATION
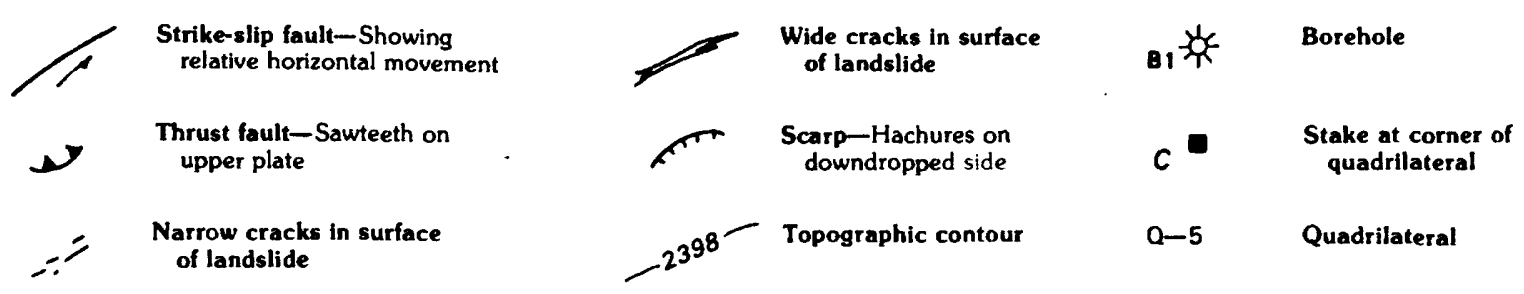

Figure B14. Map showing part of the Aspen Grove landslide in the vicinity of Q-5 during August 1984 (area "c", shown in fig. B6).

measurements can be made rapidly. In the heavily wooded terrain of the Aspen Grove landslide, two people could measure 28 quadrilaterals and eight stake lines in one working day.
The equations provided in the text have general application because they treat three-dimensional displacements and large strains. Thus, the equations are more useful than graphical methods (Ragan, 1973; Ter- 


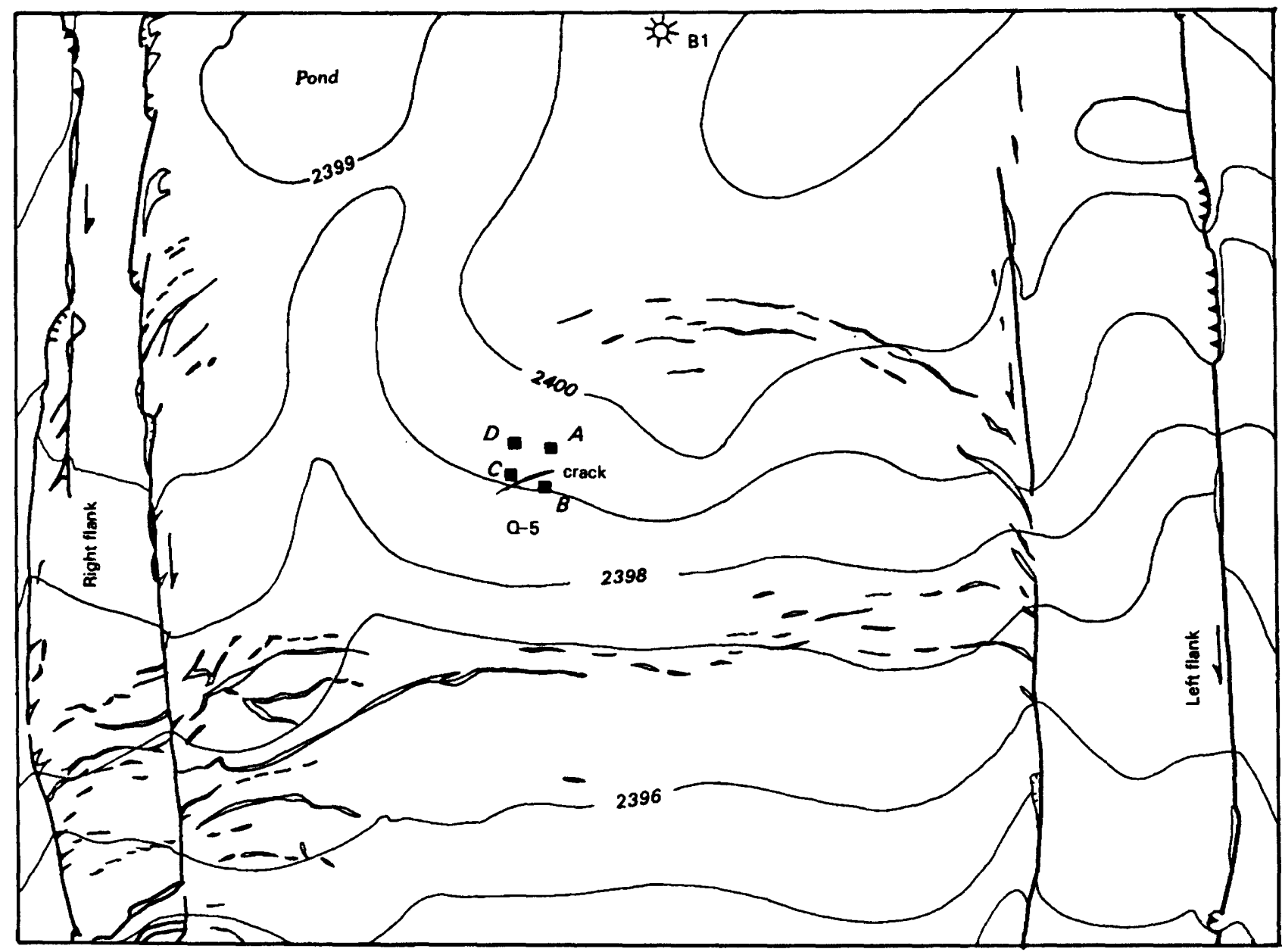

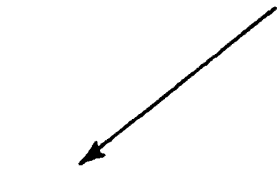

NORTH

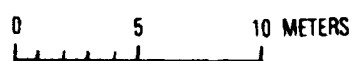

CONTOUA INTEAVAL 1 METER

EXPLANATION
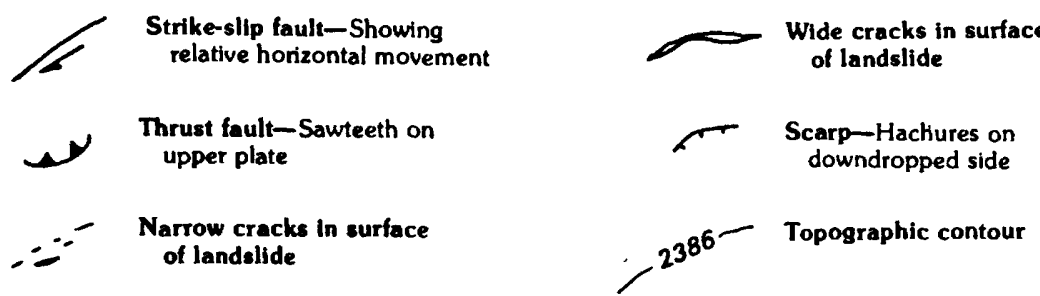

B1 花 Borehole

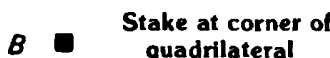

Q-5 Quadrilateral

Figure B15. Map showing part of the Aspen Grove landslide in the vicinity of Q-5 during August 1985 (area " $c$ ", shown in fig. B6).

Stepanian and Ter-Stepanian, 1974). BASIC computer programs are available for processing the data (Johnson and Baum, 1987).

When we installed the first few quadrilaterals, we hoped to measure strains and displacements in a simple way. As data accumulated, it was obvious that strains and displacements could be measured, and we began asking questions that required more data and better precision in the measurements. A few simple improvements would have resulted in a better data set.

We should have used something sturdier than 13 by $40 \mathrm{~mm}$ (nominal $1^{*}$ by $2^{*}$ ) wooden stakes and should 

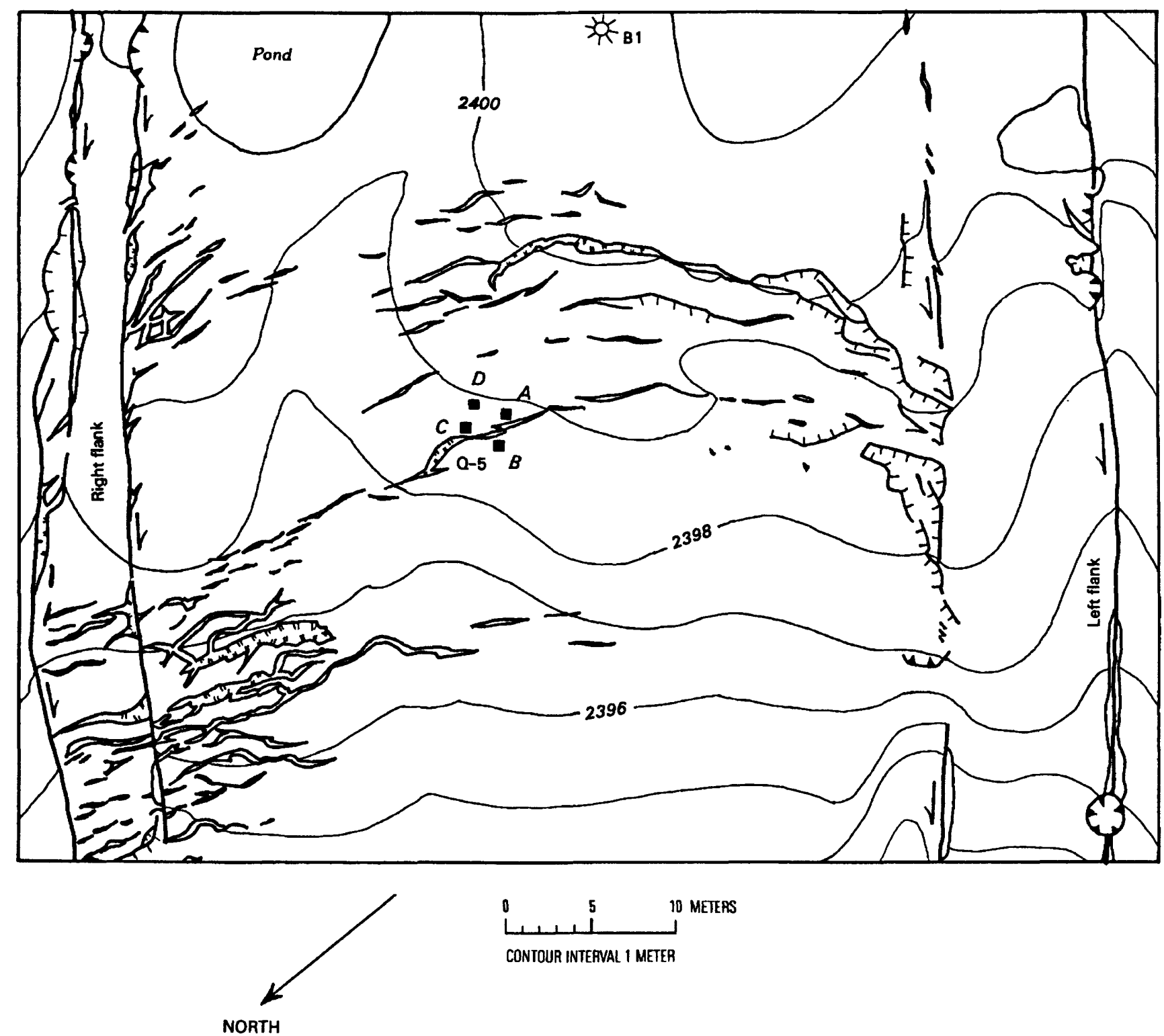

EXPLANATION
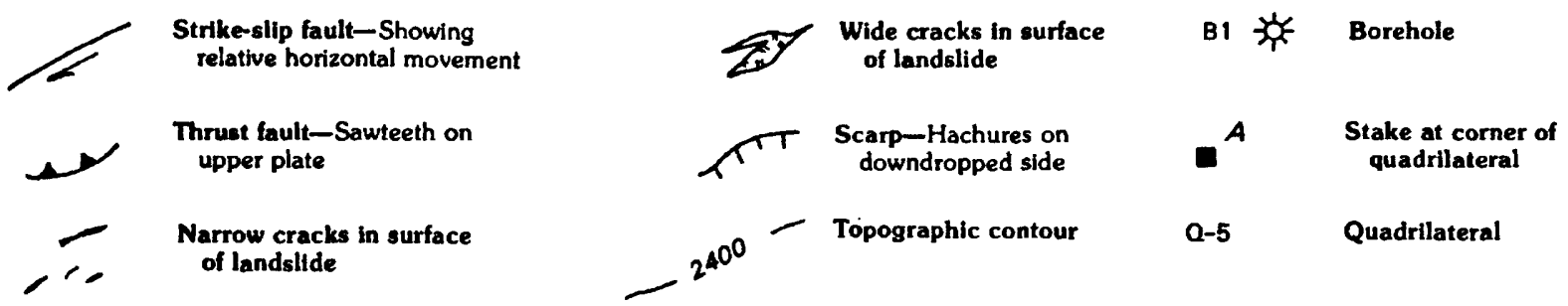

Figure B16. Map showing part of the Aspen Grove landslide in the vicinity of Q-5 during September 1986 (area "c", shown in fig. B6).

have used metal tags with numbers stamped into them to identify the stakes. Several alternatives are available, from sturdier wooden stakes to elaborate concrete and metal stakes having machined heads that accept tape or rod extensiometers.
During years when the landslide was visited infrequently, we should have replicated measurements during each visit in order to eliminate large errors that resulted from careless mistakes. Measurements were made with a tape that was marked in feet and inches, thus 
it was easy to make mistakes when reading the tape or recording the measurement. Errors in measurements caused by such mistakes were frequently large enough to interfere with strain computations; thus, repeated measurements would have improved the quality of our data sets.

Replication of measurements and application of tension and temperature corrections to measurements made with a steel tape would have improved sensitivity to small strains. Greater accuracy and sensitivity could have been achieved by making measurements with a tape extensiometer or rod extensiometer (Franklin, 1984; Hanna, 1985) so that strains as small as $0.0001(0.01$ percent strain) could be computed accurately. Quadrilateral measurements obtained by such means would be amenable to correction by least squares (Laurila, 1983) or Ingram's (1972) method of angular value weighting.

We should have replaced the stakes on moving ground next to strike-slip faults at the end of each season to keep the quadrilaterals as nearly equidimensional as possible, because measurement errors increased when the quadrilaterals became stretched into narrow diamond-shaped figures.

We should have taken photographs, and made sketches and detailed maps to show how some of the sites changed through time. The magnitudes of strains and displacements that result in visible changes to the ground surface are poorly known. Carefully drawn sketches and large-scale maps of the quadrilateral sites might have been even more useful than the photographs, because they would have insured that we studied the sites carefully and thoughtfully.

Planning is an important aspect of the field technique. We tried to view each quadrilateral as an experiment that had at least one specific question to be answered. Observations made during a visit to the site usually prompted questions. Quadrilaterals were then designed and surveyed in order to answer these questions. In some cases, we may not have asked significant questions, but we always learned something from the quadrilaterals as we measured and observed changes in them.

Once we had questions in mind, we tried to position and configure the quadrilaterals so that they would give optimum response to the deformations. Thus, quadrilaterals used to measure displacements were positioned at several locations on the boundaries and they were configured so that two sides were approximately parallel to the discontinuity at the boundary. Likewise, quadrilaterals used to measure strain and tilt were positioned on deformational features that were poorly understood or in uncomplicated areas where the background pattern of deformation could be observed. Quadrilaterals used to measure strain and tilt were configured and sized to fit the feature being measured.

During the courše of measuring and observing the quadrilaterals, our understanding of the landslide increased and new questions presented themselves. As these questions arose, we evaluated the adequacy of our quadrilaterals to answer the new questions. In some cases, the new questions could be answered with more quadrilaterals; in other cases, the questions could be answered only by other types of measurements or observations.

\section{APPENDIX}

Because analytic expressions for computing the magnitudes and directions of principal stretches from the stretches in three arbitrary directions are not available in any standard references, we present a brief derivation.

Equation 6, in the text, can be rewritten using the notation of figure B3:

$$
\begin{gathered}
\left(1 / S_{A B}{ }^{2}\right)=\left(1 / S_{1}{ }^{2}\right) \cos ^{2}\left(\beta_{A B}\right) \\
+\left(1 / S_{2}{ }^{2}\right) \sin ^{2}\left(\beta_{A B}\right), \\
\left(1 / S_{B C}{ }^{2}\right)=\left(1 / S_{1}{ }^{2}\right) \cos ^{2}\left(\beta_{B C}\right) \\
+\left(1 / S_{2}{ }^{2}\right) \sin ^{2}\left(\beta_{B C}\right),
\end{gathered}
$$

and

$$
\begin{aligned}
& \left(1 / S_{A C}{ }^{2}\right)=\left(1 / S_{1}{ }^{2}\right) \cos ^{2}\left(\beta_{A C}\right) \\
& +\left(1 / S_{2}{ }^{2}\right) \sin ^{2}\left(\beta_{A C}\right)
\end{aligned}
$$

Equations A1a, A1b, and A1c can be rewritten by using trigonometric identities that relate $\cos (2 \beta)$ to $\cos ^{2}(\beta)$ and $\sin ^{2}(\beta)$, and by making the substitution (fig. B3):

$$
\begin{gathered}
\alpha+\theta_{i}=\beta_{i}, \\
\left(1 / S_{A B}{ }^{2}\right)=(1 / 2)\left\{\left[1 / S_{1}{ }^{2}+1 / S_{2}{ }^{2}\right]\right. \\
\left.+\left[1 /{S_{1}}^{2}-1 / S_{2}{ }^{2}\right] \cos 2\left(\alpha+\theta_{A B}^{\prime}\right)\right\},
\end{gathered}
$$




$$
\begin{gathered}
\left(1 / S_{B C}{ }^{2}\right)=(1 / 2)\left\{\left[1 / S_{1}{ }^{2}+1 / S_{2}{ }^{2}\right]\right. \\
\left.+\left[1 / S_{1}{ }^{2}-1 / S_{2}{ }^{2}\right] \cos 2\left(\alpha+\theta_{B C}^{\prime}\right)\right\}
\end{gathered}
$$

and

$$
\begin{gathered}
\left(1 / S_{A C}{ }^{2}\right)=(1 / 2)\left\{\left[1 / S_{1}{ }^{2}+1 / S_{2}{ }^{2}\right]\right. \\
\left.+\left[1 /{S_{1}}^{2}-1 / S_{2}{ }^{2}\right] \cos (2 \alpha)\right\} .
\end{gathered}
$$

Subtracting equations $2 b$ from $2 a$, and $A 2 c$ from $2 a$, yields:

$$
\begin{gathered}
1 / S_{A B}{ }^{2}-1 / S_{B C}{ }^{2}=\left(1 / S_{1}{ }^{2}-1 / S_{2}{ }^{2}\right)\left\{\cos 2\left(\alpha+\theta_{A B}^{\prime}\right)\right. \\
\left.-\cos 2\left(\alpha+\theta_{B C}^{\prime}\right)\right\} ; \quad \text { (A3a) } \\
1 / S_{A B}{ }^{2}-1 / S_{A C}{ }^{2}=\left(1 / S_{1}{ }^{2}-1 / S_{2}{ }^{2}\right) \\
\left\{\cos 2\left(\alpha+\theta_{A B}^{\prime}\right)-\cos (2 \alpha)\right\} . \quad \text { (A3b) }
\end{gathered}
$$

Dividing equation $3 a$ by $3 b$ yields:

$\frac{1 / S_{A B}{ }^{2}-1 / S_{B C}{ }^{2}}{1 / S_{A B^{2}}-1 / S_{A C}{ }^{2}}=\begin{gathered}\cos 2\left(\alpha+\theta_{A B}^{\prime}\right)-\cos 2\left(\alpha+\theta_{B C}^{\prime}\right) \\ \cos 2\left(\alpha+\theta_{A B}^{\prime}\right)-\cos (2 \alpha) .\end{gathered}$

We use the angle addition formula for cosines to isolate terms containing $\alpha$ and rearrange equation 4 to solve for $\alpha$. Thus,

$$
\begin{gathered}
\alpha=(1 / 2) \tan ^{-1}\left\{\left[\left(\cos \left(2 \theta_{A B}^{\prime}\right)-1\right)\right.\right. \\
\left(1 / S_{A B}{ }^{2}-1 / S_{B C}{ }^{2}\right) / \\
\left.\left(1 / S_{A B}{ }^{2}-1 / S_{A C}{ }^{2}\right)+\cos \left(2 \theta_{B C}^{\prime}\right)-\cos \left(2 \theta_{A B}^{\prime}\right)\right] \\
/\left[\sin \left(2 \theta_{A B}^{\prime}\right)\left(1 / S_{A B}{ }^{2}-1 / S_{B C}{ }^{2}\right) /\left(1 / S_{A B}{ }^{2}-1 / S_{A C}{ }^{2}\right)\right. \\
\left.\left.+\sin \left(2 \theta_{B C}^{\prime}\right)-\sin \left(2 \theta_{A B}^{\prime}\right)\right]\right\} .
\end{gathered}
$$

Because $\alpha$ is the angle between the final orientation of $A C$ and the major principal stretch direction, the angles $\theta_{A B}^{\prime}$ and $\theta_{B C}^{\prime}$ are computed for the final shape of the triangle.

After finding $\alpha$, we substitute $\alpha$ into equations 3a and $3 \mathrm{~b}$ and rearrange them to get $S_{1}$ and $S_{2}$ :

$$
\begin{gathered}
S_{1}=1 /\left\{\left(1 / S_{A C}{ }^{2}\right)+\left(1 / S_{A B}{ }^{2}-1 / S_{B C}{ }^{2}\right)(1-\cos (2 \alpha))\right. \\
\left./\left(\cos 2\left(\alpha+\theta_{A B}^{\prime}\right)-\cos 2\left(\alpha+\theta_{B C}^{\prime}\right)\right)\right\}^{(1 / 2)} ;(\mathrm{A} 6)
\end{gathered}
$$

$$
\begin{gathered}
S_{2}=1 /\left\{\left(1 / S_{A C}{ }^{2}\right)-\left(1 / S_{A B}{ }^{2}-1 / S_{B C}{ }^{2}\right)(1+\cos (2 \alpha))\right. \\
\left./\left(\cos 2\left(\alpha+\theta_{A B}^{\prime}\right)-\cos 2\left(\alpha+\theta_{B C}^{\prime}\right)\right)\right\}^{(1 / 2)} \cdot(\mathrm{A} 7)
\end{gathered}
$$

In the event that all four corners of a quadrilateral are coplanar, a least-squares method can be used to find a single set of best-fit values for $S_{1}, S_{2}$, and $\alpha$ that apply to the entire quadrilateral. Equations $2 a, 2 b$, and $2 \mathrm{c}$ are simplified by applying the angle-addition formula:

$$
\begin{gathered}
2 / S_{i}{ }^{2}=\left(1 /{S_{1}}^{2}+1 / S_{2}{ }^{2}\right)+\left(1 / S_{1}{ }^{2}-1 / S_{2}{ }^{2}\right) \\
\cos (2 \alpha) \cos \left(2 \theta_{i}^{\prime}\right) \\
-\left(1 /{S_{1}}^{2}-1 /{S_{2}}^{2}\right) \sin (2 \alpha) \sin \left(2 \theta_{i}^{\prime}\right)
\end{gathered}
$$

We have an equation of the form:

$$
z=c+c_{1} x+c_{2} y
$$

in which

and

$$
\begin{gathered}
\mathrm{c}=\left(1 /{S_{1}}^{2}+1 /{S_{2}}^{2}\right) \\
c_{1}=\left(1 /{S_{1}}^{2}-1 /{S_{2}}^{2}\right) \cos (2 \alpha)
\end{gathered}
$$

$$
c_{2}=-\left(1 / S_{1}{ }^{2}-1 / S_{2}{ }^{2}\right) \sin (2 \alpha) \text {. }
$$

Applying stanclurd methods for least squares results in three equations that can be solved for $c, c_{1}$, and $c_{2}$ and, hence, $\alpha, S_{1}$, and $S_{2}$. 


\section{REFERENCES CITED}

Brinker, R.C., and Wolf, P.R., 1977, Elementary surveying, in the collection The IEP series in civil engineering, 6th edition: New York, Thomas Y. Crowell Co., 568 p.

Brunsden, D., 1984, Mudslides, in Brunsden, D. and Prior, D.B., eds., Slope instability: New York, John Wiley, p. 363-418.

Carter, M., and Bentley, S.P., 1985, The geometry of slip surfaces beneath landslides-Predictions from surface measurements: Canadian Geotechnical Journal, v. 22, p. 234-238.

Cruden, D.M., 1986, The geometry of slip surfaces beneath landslides-Predictions from surface measurements -Discussion: Canadian Geotechnical Journal, v. 23, p. 94.

Franklin, J.A., 1984, Slope instrumentation and monitoring, in Brunsden, D., and Prior, D.B., eds., Slope instability: New York, John Wiley, p. 143-170.

Hanna, T.H., 1985, Field instrumentation in geotechnical engineering, in Series on Rock and Soil Mechanics, v. 10: Rockport, Maine, Trans Tech Publications, 843 p.

Ingram, F.L., 1972, The Ingram method of angular value weighting in trilateration: Surveying and Mapping, v. 32, p. 509-515.

Iverson, R.M., 1984, Unsteady, nonuniform landslide motion- Theory and measurement: Stanford, Calif., Stanford University Ph.D. thesis, 303 p.

Jaeger, J.C., 1962, Elasticity, fracture, and flow, 2nd edition: London, Methuen, and New York, John Wiley, 208 p.
Johnson, A.M., and Baum, R.L., 1987, BASIC programs for computing displacements, strains, and tilts from quadrilateral measurements: U.S. Geological Survey Open-File Report 87-343, 19 p.

Keefer, D.K., and Johnson, A.M., 1983, Earth flows-Morphology, mobilization, and movement: U.S. Geological Survey Professional Paper 1264, 56 p.

Lantz, J.R., 1984, Geology and kinematics of a clay-rich landslide with an undulatory slip surface: College Station, Texas, Texas A \& M University M.S. thesis, 132 p.

Laurila, S.H., 1983, Electronic surveying in practice: New York, John Wiley, 388 p.

Malvern, L.E., 1969, Introduction to the mechanics of a continuous medium: Englewood Cliffs, New Jersey, Prentice Hall, 713 p.

Ragan, D.M., 1973, Structural geology, an introduction to geometrical techniques: New York, John Wiley, 208 p.

Ramsay, J.G., 1967, Folding and fracturing of rocks: New York, McGraw -Hill, 568 p.

Ter-Stepanian, G., 1984, Analysis of slope deformation for determining the landslide mechanism, in Proceedings of the Fourth International Symposium on Landslides, v. 2: Downview, Ontario, Canada, University of Toronto Press, p. 499-504.

Ter-Stepanian, G., and Ter-Stepanian, H., 1974, Determination of deformed state of a sliding body by creep hodographs, in Proceedings of the Second International Congress of the International Association of Engineering Geology: Sao Paulo, Brazil, v. II, p. V23.1-V23.5.

Zaruba, Q., and Mencl, V., 1982, Landslides and their control, 2nd revised edition: New York, Elsevier, 324 p. 





\section{SELECTED SERIES OF U.S. GEOLOGICAL SURVEY PUBLICATIONS}

\section{Perlodicals}

Earthquakes \& Volcanoes (issued bimonthly).

Preliminary Determination of Epicenters (issued monthly).

\section{Technicai Books and Reports}

Professional Papers are mainly comprehensive scientific reports of wide and lasting interest and importance to professional scientists and engineers. Included are reports on the results of resource studies and of topographic, hydrologic, and geologic investigations. They also include collections of related papers addressing different aspects of a single scientific topic.

Bulletins contain significant data and interpretations that are of lasting scientific interest but are generally more limited in scope or geographic coverage than Professional Papers. They include the results of resource studies and of geologic and topographic investigations; as well as collections of short papers related to a specific topic.

Water-Supply Papers are comprehensive reports that present significant interpretive results of hydrologic investigations of wide interest to professional geologists, hydrologists, and engineers. The series covers investigations in all phases of hydrology, including hydrogeology, availability of water, quality of water, and use of water.

Circulars present administrative information or important scientific information of wide popular interest in a format designed for distribution at no cost to the public. Information is usually of short-term interest.

Water-Resources Investigations Reports are papers of an interpretive nature made available to the public outside the formal USGS publications series. Copies are reproduced on request unlike formal USGS publications, and they are also available for public inspection at depositories indicated in USGS catalogs.

Open-File Reports include unpublished manuscript reports, maps, and other material that are made available for public consultation at depositories. They are a nonpermanent form of publication that may be cited in other publications as sources of information.

\section{Maps}

Geologic Quadrangle Maps are multicolor geologic maps on topographic bases in 7 1/2-or 15-minute quadrangle formats (scales mainly $1: 24,000$ or $1: 62,500$ ) showing bedrock, surficial, or engineering geology. Maps generally include brief texts; some maps include structure and columnar sections only.

Geophysical Investigations Maps are on topographic or planimetric bases at various scales; they show results of surveys using geophysical techniques, such as gravity, magnetic, seismic, or radioactivity, which reflect subsurface structures that are of economic or geologic significance. Many maps include correlations with the geology.

Miscellaneous Investigations Series Maps are on planimetric or topographic bases of regular and irregular areas at various scales; they present a wide variety of format and subject matter. The series also includes 7 1/2-minute quadrangle photogeologicmaps on planimetric bases which show geology as interpreted from aerial photographs. Series also includes maps of Mars and the Moon.
Coal Investigations Maps are geologic maps on topographic or planimetric bases at various scales showing bedrock or surficial geology, stratigraphy, and structural relations in certain coal-resource areas.

Oil and Gas Investigations Charts show stratigraphic information for certain oil and gas fields and other areas having petroleum potential.

Miscellaneous Field Studies Maps are multicolor or black-andwhite maps on topographic or planimetric bases on quadrangle or irregular areas at various scales. Pre-1971 maps show bedrock geology in relation to specific mining or mineral-deposit problems; post-1971 maps are primarily black-and-white maps on various subjects such as environmental studies or wildemess mineral investigations.

Hydrologic Investigations Atlases are multicolored or black-andwhite maps on topographic or planimetric bases presenting a wide range of geohydrologic data of both regular and irregular areas; principal scale is $1: 24,000$ and regional studies are at $1: 250,000$ scale or smaller.

\section{Catalogs}

Permanent catalogs, as well as some others, giving comprehensive listings of U.S. Geological Survey publications are available under the conditions indicated below from the U.S. Geological Survey, Books and Open-File Reports Section, Federal Center, Box 25425, Denver, CO 80225. (See latest Price and Availability List)

"Publications of the Geological Survey, 1879-1961" may be purchased by mail and over the counter in paperback book form and as a set of microfiche.

"Publications of the Geological Survey, 1962-1970" may be purchased by mail and over the counter in paperback book form and as a set of microfiche.

"Publications of the U.S. Geological Survey, 1971-1981" may be purchased by mail and over the counter in paperback book form (two volumes, publications listing and index) and as a set of microfiche.

Supplements for 1982, 1983, 1984, 1985, 1986, and for subsequent years since the last permanent catalog may be purchased by mail and over the counter in paperback book form.

State catalogs, "List of U.S. Geological Survey Geologic and Water-Supply Reports and Maps For (State)," may be purchased by mail and over the counter in paperback booklet form only

"Price and Availability List of U.S. Geological Survey Publications," issued annually, is available free of charge in paperback booklet form only.

Selected copies of a monthly catalog "New Publications of the U.S. Geological Survey" available free of charge by mail or may be obtained over the counter in paperback booklet form only. Those wishing a free subscription to the monthly catalog "New Publications of the U.S. Geological Survey" should write to the U.S. Geological Survey, 582 National Center, Reston, VA 22092.

Note.--Prices of Government publications listed in older catalogs, announcements, and publications may be incorrect. Therefore, the prices charged may differ from the prices in catalogs, announcements, and publications. 


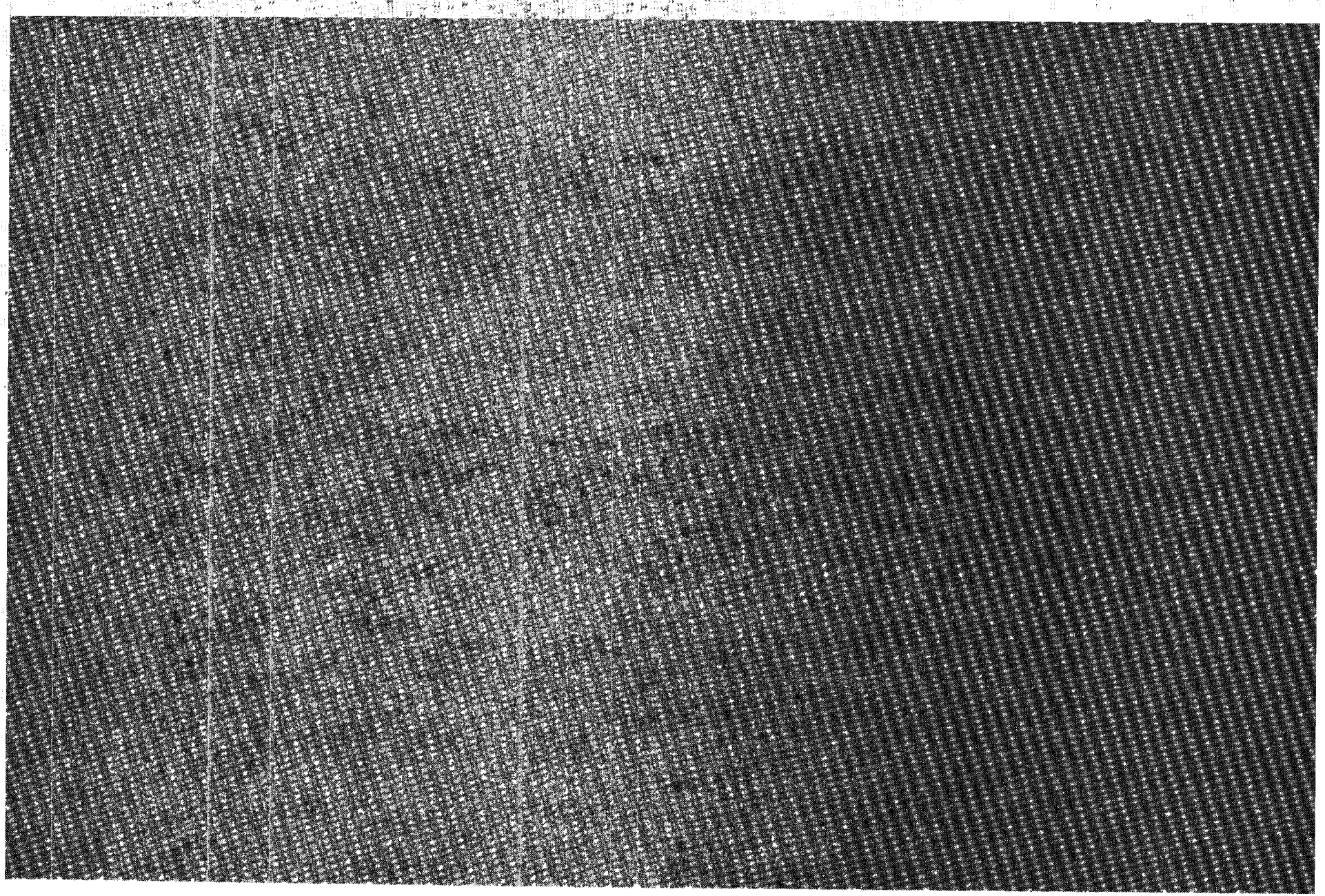

